Document downloaded from:

http://hdl.handle.net/10251/62924

This paper must be cited as:

Oroian, M.; Escriche Roberto, MI. (2015). Antioxidants: Characterization, natural sources, extraction and analysis. Food Research International. 74:10-36. doi:10.1016/j.foodres.2015.04.018.

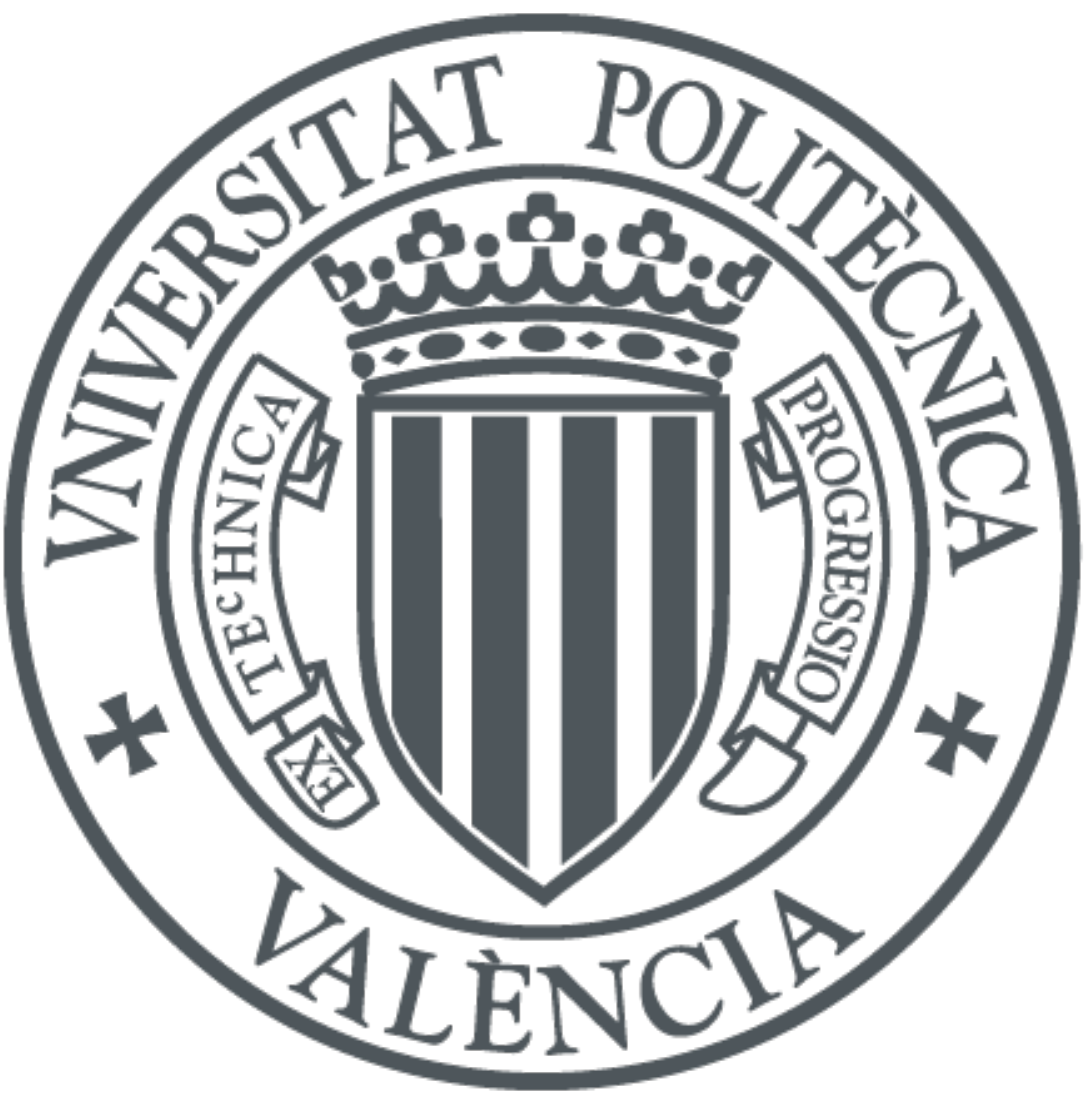

The final publication is available at

http://dx.doi.org/10.1016/j.foodres.2015.04.018

Copyright Elsevier

Additional Information 


\title{
Antioxidants: characterization, natural sources, extraction and analysis
}

\author{
Mircea Oroian $^{1 *}$, Isabel Escriche ${ }^{2}$ \\ ${ }^{1}$ Faculty of Food Engineering, Stefan cel Mare University of Suceava, Suceava, Romania \\ ${ }^{2}$ Institute of Food Engineering for Development (IUIAD). Food Technology Department (DTA). \\ Universitat Politècnica de València. Valencia, Spain \\ Corresponding author: m.oroian@fia.usv.ro (Mircea Oroian)
}

\begin{abstract}
Antioxidants from fruits, vegetables and beverages play an important role in human health, for example preventing cancer and cardiovascular diseases, and lowering the incidence of different diseases. In this paper the main classes of antioxidants are presented: vitamins ( vitamin $\mathrm{C}$ and vitamin E); carotenoids; polyphenols (flavonoids, flavonols, flavones, flavanones, anthocyanins, isoflavones); phenolic acids; tannins; stilbenes; and lignans. Recently, many analytical methodologies involving diverse instrumental techniques have been developed for the extraction, separation, identification and quantification of these compounds. The main methods of antioxidant extraction are: extraction with solvents, extraction with supercritical fluids, microware-assisted extraction, subcritical water extraction, ultrasonics, pulsed electric fields, high hydrostatic pressure, high voltage electrical discharges and enzyme-assisted extraction. Antioxidants have been quantified by different researchers using one or more of these methods: in vivo, in vitro, electrochemical, chemiluminescent, electron spin resonance, chromatography,
\end{abstract}


capillary electrophoresis, nuclear magnetic resonance, near infrared spectroscopy and mass spectrometry methods.

Keywords: antioxidant, natural sources, analysis

\section{Introduction}

Antioxidants found in food are a heterogeneous category of molecules (Tuberoso et al. 2012). Antioxidants are compounds or systems that can safely interact with free radicals and terminate the chain reaction before vital molecules are damaged. They can use several mechanisms: (i) scavenging species that initiate peroxidation, (ii) chelating metal ions so that they are unable to generate reactive species or decompose peroxides, (iii) quenching ${ }^{*} \mathrm{O}_{2}{ }^{-}$preventing formation of peroxides, (iv) breaking the auto-oxidative chain reaction, and/or (v) reducing localized $\mathrm{O}_{2}$ concentrations (Nawar, 1996, Sakanaka, Tachibana \& Okada 2005, Asimi, Sahu \& Pal 2013). The anti-oxidative effectiveness of these compounds depends on their chemical characteristics and physical location within a food (proximity to membrane phospholipids, emulsion interfaces, or in the aqueous phase) (Watanabe et al. 2000). Antioxidants (e.g., flavonoids, phenolic acids, tannins, vitamin C, vitamin E) have diverse biological properties, such as anti-inflammatory, anti-carcinogenic and anti-atherosclerotic effects, and also reduce the incidence of coronary diseases (Brezová, Šlebodová \& Staškp 2009, Boffetta et al. 2010, Fu et al. 2011, Díaz et al. 2011, Zhao et al. 2010, Li \& Beta, 2011, Bartoszek \& Polak, 2012, Strati \& 
Oreopoulou, 2011, Ratnasooriya \& Rupasinghe, 2012, Toro-Funes et al. 2012, Fernández-Marín et al. 2012, Machmudah et al. 2012, Hamrouni-Sellami et al. 2012).

The aim of this study is to describe: the main classes of antioxidants existing in fruit, beverages, vegetables and herbs; the different procedures to determine total antioxidant activity; and the different extraction, separation and quantification procedures used to evaluate their presence in food.

\section{Classification of antioxidants}

Antioxidants cover different classes of compounds which can interfere with oxidative cycles to inhibit or retard the oxidative damage of biomolecules. The major classes of compounds with antioxidant activity are: vitamins (vitamin $\mathrm{C}$ and vitamin $\mathrm{E}$ ), carotenoids (carotenes and xanthophylls) and polyphenols (flavonoids, flavonols, flavones, flavanones, anthocyanins, isoflavones, phenolic acids, tannins, stilbenes and lignans).

\subsection{Vitamins}

2.1.1. Vitamin C. Vitamin C (L-ascorbic acid; hereafter, 'ascorbic acid' and 'ascorbate' refer to 'L-(+)-ascorbic acid' and 'L-ascorbate Fig. 1a) is unique among vitamins for several reasons. It is believed to be the most important hydrophilic antioxidant (Lykkesfeldt 2000) being effective in scavenging superoxide radical anions, hydroxyl radicals, hydrogen peroxide, reactive nitrogen species and singlet oxygen. Vitamin $\mathrm{C}$ can acts as a reactive oxygen species (ROS) scavenger ( $>1000 \mathrm{mg} / \mathrm{kg})$ and inhibits oxidation, however, at low levels, vitamin $\mathrm{C}(<100 \mathrm{mg} / \mathrm{kg})$ can catalyze oxidation (in muscle tissue) (Ahn, Grun \& Mustapha 2007).

Vitamin $\mathrm{C}$ has, at a structural level, $4-\mathrm{OH}$ groups which can donate hydrogen to an oxidizing system (Brewer, 2011). Resonance forms can also be written for the form of vitamin C 
that has lost one electron, making the radical semidehydroascorbate (SDA) much more stable, and thus much less reactive, than most other free radicals (Buettner, 1993).

The antioxidant mechanism of vitamin $\mathrm{C}$ was proposed by Bendlich, Machlin \& Scandura (1986). At $\mathrm{pH} 7$, the ascorbate anion $\left(\mathrm{AH}^{-}\right)$is the predominant form present, due to the acidic nature of ascorbic acid $\left(\mathrm{AH}_{2}\right)$. This compound can undergo a reversible oxidation process and form dehydroascorbic acid (A), with ascorbyl radical formation $\left(\mathrm{A}^{-}\right)$. The ascorbyl radical is relatively unreactive and may react with other free radicals and the propagation of free radical reactions may be stopped (eq. 1):

$$
2 A^{-\cdot}+H^{+} \rightarrow A H^{-}+A^{*}
$$

The reaction between the peroxyl radicals and ascorbate has been proposed as (Bendlich, Machlin \& Scandura 1986):

$$
\begin{aligned}
& R O O+\mathrm{AH}^{-} \rightarrow \mathrm{ROOH}+A^{-\cdot}(2) \\
& A^{-\cdot}+\mathrm{O}_{2} \rightarrow \mathrm{A}+\mathrm{O}_{2}^{-\cdot}(3) \\
& \mathrm{O}_{2}^{-\cdot}+\mathrm{ROO}+\mathrm{H}^{+} \rightarrow \mathrm{O}_{2}+\mathrm{ROOH}(4) \\
& \mathrm{O}_{2}^{-\cdot}+\mathrm{AH}^{-}+H^{+} \rightarrow \mathrm{H}_{2} \mathrm{O}_{2}+A^{+\cdot}(5) \\
& A^{-\cdot}+\mathrm{ROO}^{\cdot}+H^{+} \rightarrow A+\mathrm{ROOH}(6)
\end{aligned}
$$

Ascorbate efficiency is higher at low concentrations (one molecule of ascorbate can trap 2 molecules of peroxyl radical), while at high concentrations the efficiency is 0 . The superoxide anion (reaction 4) or the ascorbyl radical (reaction 6) reacts with a peroxyl radical at very low concentrations of ascorbate. At higher concentrations of ascorbate, reaction 4propagation competes with the chain termination reactions 4 and 6 . This "wastes" the ascorbate, and lowers its efficiency (Bendlich, Machlin \& Scandura, 1986). The Food and Agriculture Organization (FAO/WHO, 2001) indicate that the Dietary References Intake of vitamin C ranges from 25 to 45 
$\mathrm{mg} /$ day, depending on age. Vitamin $\mathrm{C}$ content can vary widely, according to environmental factors (Burgos et al. 2009), climate (Vallejo, Tomas-Barberan, Garcia-Viguera 2003), storage (Burgos et al. 2009) and cooking conditions (Burgos et al. 2009, Francisco et al. 2010, Barros et al. 2011). The main sources of vitamin $\mathrm{C}$ and its health benefits are presented in Table 1.

2.1.2. Vitamin E. The term vitamin $\mathrm{E}$ refers to a group of chemical compounds (tocopherols and tocotrienols). Vitamin E (Fig. 1b) is generally accepted to be the primary lipidsoluble antioxidant in humans and acts as an antioxidant via two primary mechanisms: (i) a chainbreaking electron donor (CB-D) mechanism and (ii) a chain-breaking acceptor (CB-A) mechanism. The antioxidant capacity of $\alpha$-tocopherol has been studied (Thoo et al. 2013), observing that its activity depends on parboiling, storage and cooking (Pascual et al. 2013) and genotype (Beltrán et al. 2010, Chung et al. 2013).

Vitamin $\mathrm{E}$ is formed by four tocopherols and four tocotrienols, which exhibit chainbreaking antioxidant activity. The tocopherols group exhibit the antioxidant activity (van Acker, Koymans \& Bast, 1993). Burton \& Ingold (1981) proposed that the self-initiated autooxidation depends on the number of the phenol ( $\mathrm{ArOH})$ toward (ROO), on the number of radicals trapped per phenol (n), and on the occurrence of chain transfer.

$\mathrm{ArO}+\mathrm{RH} \rightarrow \mathrm{ArOH}+\mathrm{R}^{\cdot}(7)$

The peroxyl radicals are being trapped:

$$
\mathrm{ROO}+\mathrm{ArOH} \stackrel{k_{1}}{\rightarrow} \mathrm{ROOH}+\mathrm{ArO} .
$$

The phenoxyl radicals (ArO) are resonance stabilized and do not continue the chain. In some cases the phenoxyl radicals may react with a second peroxyl radical:

$$
\begin{aligned}
& \mathrm{ROO}+\mathrm{ArO} \stackrel{k_{2}}{\rightarrow} \text { molecular products }(9) \\
& k_{1} \text { and } k_{2} \text { - reaction rate constant }
\end{aligned}
$$


The Food and Agriculture Organization (FAO/WHO, 2001) suggests that the recommended nutrient intake of vitamin $\mathrm{E}$ is $8-25 \mathrm{mg} /$ day.

The main sources of vitamin $\mathrm{E}$ and its health benefits are presented in Table 1.

\subsection{Carotenoids}

At least 60 carotenoids occur in fruit and vegetables consumed by humans. The main carotenoids present in the daily diet are: $\alpha$ - and $\beta$-carotene lycopene (as carotenoids) and the hydroxy carotenoids (xanthophylls - zeaxanthin and lutein). Carotenoids are important not only for their provitamin A activity, but also for a spectrum of other actions in biological systems. Like tocopherols (Kaiser, Di Mascio, Murphy \& Sies 1990), carotenoids and xanthophylls are effective ${ }^{1} \mathrm{O}_{2}$ (singlet oxygen) quenchers.

The carotenoids have been considered the most powerful quenchers of singlet oxygen, they can react with any of the radical species which are present in the biological system such as superoxide anion or nitrogen oxides. In the majority of these reactions, carotenoids break down to biologically active degradation products (Krinsky \& Yeum, 2003).

The reaction mechanism of carotenoids with radical species involves: radical addition, electron transfer to the radical or allylic hydrogen abstraction.

Radical addition: adduct formation. The mechanism was proposed by Burton \& Ingold (1984). The mechanism supposes that the lipid peroxyl radical (ROO) might be added at any place along the carotenoid (CAR) polyene chain:

$$
R O O+C A R \rightarrow R O O-C A R \cdot(10)
$$


The component obtained is a carbon-centred radical. However, it is thought that the carboncentred radical may react reversibly with $\mathrm{O}_{2}$ by forming a new peroxyl radical (Krinsky \& Yeum, 2003):

$R O O-C A R+O_{2} \leftrightarrow R O O-C A R-O O$

Electron transfer. The reaction products are cation radicals $\mathrm{CAR}^{+}$, anion radicals, $\mathrm{CAR}^{-}$, or alkyl radicals, CAR· (El-Agamey et al. 2004):

$$
C A R+R O O^{\cdot} \rightarrow C^{++}+R^{-}(12)
$$

Allylic hydrogen abstraction. This process was suggested by Woodall et al. (1997) and involves the following mechanism:

$$
\begin{aligned}
& C A R+R O O \rightarrow C A R+R O O H \\
& C A R+\mathrm{CH}_{3} \mathrm{OH} \rightarrow \mathrm{CAR}-\mathrm{OCH}_{3}+\mathrm{H}^{+}(14)
\end{aligned}
$$

The main sources of carotenoids and its health benefits are presented in Table 1.

\subsubsection{Carotenoids}

$\boldsymbol{\beta}$-carotene. $\beta$-carotene, a lipid-soluble provitamin, (Fig.2a) is composed of two retinyl groups, and is broken down in the mucosa of the human small intestine to retinal, a form of vitamin A (Tang et al. 1991, Hosotani \& Kitagawa, 2003). It is one of the most powerful antioxidants, being capable of blocking singlet oxygen and inhibiting lipid oxidation (Samaniego-Sánchez et al. 2010).

Foote and co-workers (1968, 1971), and Farmilo and Wilkenson (1973) found that the quenching of ${ }^{1} \mathrm{O}_{2}$ by $\beta$-carotene was due to an efficient energy transfer from ${ }^{1} \mathrm{O}_{2}$ to $\beta$-carotene (equation 15).

$$
{ }^{1} \mathrm{O}_{2}+\beta \text {-carotene } \rightarrow{ }^{3} \mathrm{O}_{2}+{ }^{3} \beta \text {-carotene }
$$


where ${ }^{3} \mathrm{O}_{2}$ - triplet oxygen and ${ }^{3} \beta$-carotene - triplet state $\beta$-carotene.

The main sources of $\beta$-carotene and its health benefits are presented in Table 1.

Lycopene. Lycopene (Fig.2b) with eleven conjugated and two non-conjugated double bonds is the most efficient singlet oxygen quencher of the natural carotenoids (Di Mascio, Kaiser

\& Sies 1989, Krinsky, 1998). The many conjugated double bonds of lycopene make it a potentially powerful antioxidant (Arab \& Steck, 2000), a characteristic believed to be responsible for its beneficial effects. The antioxidant activity of lycopene is highlighted by its ability to trap peroxyl radicals (Omoni \& Aluko, 2005). The main sources of lycopene and its health benefits are presented in Table 1.

\subsubsection{Hydroxy-carotenoids (Xanthophylls)}

Xanthophylls are oxygenated carotenoids that are synthesized within the plastids and are commonly found as the yellow pigments of leaves. Lutein and zeaxanthin are structural isomers differing only in the configuration in one of the cyclohexene moieties that flank both terminal ends of both compounds. Lutein is chemically designated as $\beta, \varepsilon-$ carotene $-3,3^{\prime}$-diol, while zeaxanthin is designated as $\beta, \beta$ - carotene -3 , 3'-diol (Pasaporte, Rabayam Toleco \& Flores 2014). The main sources of xanthophylls and its health benefits are presented in Table 1.

\subsection{Polyphenols}

Polyphenolic compounds are ubiquitous in all plant organs and are, therefore, an integral part of the human diet. They are synthesised by the shikimate, polyketide and mevalonate pathways or mixed pathways, which produce the large variety of plant phenols. In the last part of $20^{\text {th }}$ century, 
the interest in food phenolics has increased due to their antioxidant and free radical-scavenging abilities (Bravo, 1998). Polyphenols may exert an indirect antioxidant effect, by protecting endogenous antioxidant enzymes in the human body (Stevenson \& Hurst 2007; Aron \& Kennedy 2008). Stevenson \& Hurst (2007) suggest in their review that it appears that polyphenols can provide significant protection from oxidative stress in vitro at concentrations much lower than would be required for chemical antioxidant protection (Weichselbaum \& Buttriss, 2010). The main groups of polyphenols are flavonoids, phenolic acids, phenolic alcohols, stilbenes and lignans (D’Archivio et al. 2007); their chemical structures are presented in Fig 3-12.

The mechanism for the antioxidant activity of the polyphenols has been proposed by Leopoldini, Russo \& Toscano (2011). Firstly, the polyphenol molecule inactivates free radicals according to hydrogen atom transfer and to single electron transfer mechanisms. The hydrogen atom transfer mechanism supposes that the antioxidant, $\mathrm{AaOH}$, reacts with the free radical, $\mathrm{R}$, with hydrogen atom transfer:

$$
\mathrm{AaOH}+\mathrm{R} \rightarrow \mathrm{ArO}+\mathrm{RH}(16)
$$

The other mechanism, single electron transfer, supposes that the oxidant donates an electron to the antioxidant molecule:

$$
\mathrm{AaOH}+\mathrm{R} \rightarrow \mathrm{ArOH}^{+}+\mathrm{R}^{-}(17)
$$

The reaction products of the two mechanisms are: a harmless species $(\mathrm{RH})$, an oxidised radical $(\mathrm{AaO})$, a cation radical $\left(\mathrm{AaOH}^{+}\right)$and an energetically stable species $\left(\mathrm{R}^{-}\right)$.

\subsubsection{Flavonoids}

Flavonoids (Fig. 3), many of which are plant pigments, are abundant in nature (Hendrich, 2006). Flavonoids can be further divided into several subclasses, of which the most representative are: flavones, flavanones, flavonols, flavanols (also called flavan-3-ols or catechins), 
anthocyanidins and isoflavones (Hendrich, 2006; Lotito \& Frei, 2006; D’Archivio et al. 2007). The general structure of flavonoids includes a C15 (C6-C3-C6) skeleton (Merken \& Beecher, 2000).

From a structural point of view, the flavonoids are based on a specific three-ring system, there being a central oxygen-containing pyran ring ( $\mathrm{C}$ ring) in different oxidation states. The pyran ring is fused to an aromatic ring (A Ring) along one bond and attached to another aromatic ring with a single bond (B ring). The flavonoids presented in grapes and wine have the same hydroxyl substitution groups on ring $\mathrm{A}$, at positions 5 and 7.

The flavones can be classified in several subgroups which are mainly indicated either by (i) hydroxylation, (ii) $\mathrm{O}$-methylation, (iii) $\mathrm{C}$-methylation, (iv) isoprenylation, or (v) methylenedioxy substitution. The main sources of flavonoids and their health benefits are presented in Table 1.

\section{Flavonols}

Flavonols make up the most abundant class located in Vitis vinifera grape berry skins (Haselgrove et al. 2000). Flavonols are responsible for the yellow pigment of grapes which contribute to the colour of white wines (in the case of red wines they are masked by anthocyanins) (Castillo-Muñoz et al. 2010).

Flavonols (Fig. 4) are identified by the location of the alcohol group on the $\mathrm{C}$ ring. In general, the frequent sugar moieties in flavonols are glucose, rhamnose, galactose and arabinose (Hollman \& Arts, 2000). The principal dietary flavonols are quercetin, myricetin, rutin, isorhamnetin and kaempferol. 
Flavonols are a class of flavonoid commonly found in many fruit and vegetables. Their content varies widely, depending on variety and environmental factors, such as growing conditions, growing climate, storage, light and cooking conditions (Yuan et al. 2009, Koyama et al. 2012).

One of the most important flavonols is quercetin. Quercetin, 3, 3, 4, 5, 7 pentahydroxyflavone, is present in fruit and vegetables. It occurs mainly in leaves and in the other parts of the plants as aglycones and glycosides, in which one or more sugar groups is bound to phenolic groups by a glycosidic bond. Glucose is the most common sugar, with galactose and rhamnose also frequently found in combination with flavonoids. In general, quercetin glycosides contain a sugar group at the 3-position (Wach, Pyrzynska \& Biesaga 2007).

The main sources of flavonols and their health benefits are presented in Table 1.

\section{Flavones}

Chemically, flavonols (Fig. 5) lack a 3-hydroxygroup. However, as flavones and flavonols are biosynthetically distinct flavonoid classes, only flavones will be discussed. As combinations of various modifications can occur, the number of different flavones is enormous. Flavones can be found in all parts of plants, above and below ground, in vegetative and generative organs: stem, leaves, buds, bark, heartwood, thorns, roots, rhizomes, flowers, fruit, seeds, and also in root and leaf exudates or resin (Greenham, Harborne \& Williams 2003). The main sources of flavones and their health benefits are presented in Table 1.

\section{Flavanones}

Flavanones (Fig. 6) also can occur as $O$-or $C$-glycosides and are especially abundant in citrus fruit and prunes (Bravo, 1998). Naringenin (4',5,7-trihydroxyflavanone) is a flavanone found 
predominantly in citrus fruit such as oranges and grapefruit. The main sources of flavanones and their health benefits are presented in Table 1.

\section{Anthocyanins}

Anthocyanins, the largest group of pigments in nature, are responsible for colour in fruits and flowers (Cavalcanti, Santos \& Meireles 2011, Pascual-Teresa \& Sanchez-Ballesta, 2008). Anthocyanidins when linked to one or more glycosidic units, are named antocianins.

Anthocyanidins are linked to one or more glycosidic units, being glycosylated polyhydroxy and polymethoxyderivates of 2-phenylbenzopyrylium salts (flavylium). The glycosidic units may be linked to the anthocyanidin by $\alpha$ or $\beta$ linkage, and always in position 3 of the aglycon (Fig. 7). When additional sugars are present in the anthocyanin molecule, they are linked to positions 5 and 7, and less frequently to 3' and 5'. The sugars encountered in anthocyanins can be hexoses (glucose and galactose) and pentoses (xylose, arabinose) (Pascual-Teresa \& Sanchez-Ballesta, 2008). Anthocyanin molecules are unstable and easily degraded (Giusti \& Wrolstad, 2003) by temperature, $\mathrm{pH}$, light, oxygen, solvents, metallic ions, ascorbic acid, sulphite and enzymes (Cavalcanti, Santos \& Meireles 2011).

The main sources of anthocyanins and their health benefits are presented in Table 1.

\section{Isoflavones}

Isoflavones (Fig. 8) are a group of oxygen heterocycle compounds that belong to the family of phytoestrogens (Xiao et al. 2009). The most common isoflavones are daidzein, geninstein and glycistein (Riu et al. 2008) which occur in legumes, especially in soybean (Balisteiro, Rombaldi \& Genovese 2013). The main forms of isoflavones in plants are glycosides with a sugar (e.g. 
glucose, malonylglucose, acetylglucose, galactose, rhamnose, etc The main sources of isoflavones and their health benefits are presented in Table 1.

\subsubsection{Phenolic acids}

Phenolic acids (Fig. 9) can be divided into two categories depending on their structure: derivates of benzoic acid and derivates of cinnamic acid. These compounds consist of a benzene ring bonded to a carboxylic group (benzoic acids) or to a propenoic acid (cinnamic acids). Different hydroxylation levels can be found for both structures (Lafay \& Gil-Izquiero, 2008). Hydroxybenzoic acids include gallic, $p$-hydroxy-benzoic, protocatechuic, vanilic and syringic acids. The most important hydroxycinnamic acids are caffeic, ferulic, $p$-coumaric and sinapic acids (Bravo, 1998). The main sources of phenolic acids and their health benefits are presented in Table 1.

\subsubsection{Tannins}

Tannins (Fig. 10), with a molecular mass of up to $30,000 \mathrm{Da}$, are produced by plants as secondary metabolites (Winkel-Shirley, 2001). According to their structure, tannins can be broadly divided into two classes of macromolecules, termed hydrolysable tannins and condensed tannins.

Hydrolysable tannins have a molecular mass ranging between 500 and 5000 Da (Arapitsas 2012). In addition to the astringent character (Glabasnia \& Hofman 2006), they have important antioxidant activity (Borges, Mullen \& Crozier 2010, Larrosa et al. 2010).

Condensed tannins or proanthocyanidins are high-molecular-weight polymers with a molecular mass up to $30000 \mathrm{Da}$. The monomeric form is a flavan-3-ol (catechin, epicatechin, etc.), 
with a flavan-3,4-diol or aleucoanthocyanidin molecule as its precursor. Oxidative condensation occurs between carbon C-4 of the heterocycle and carbons C-6 or C-8 of adjacent units.

The main sources of tannins and their health benefits are presented in Table 1.

\subsubsection{Stilbenes}

Stilbenes are phenolic compounds (Kostadinović et al. 2012) displaying two aromatic rings linked by an ethane bridge, and exist in monomeric (resveratrol, oxyresveratrol) and oligomeric form as oligomers of stilbenes (dimmers, trimers or polymers of resveratrol) or other stilbenes (e.g. epsilon-viniferin, pallidol, etc) (Charles, 2013).

They are important because of their health effects, which occur in lower concentrations compared to other phenolic compounds. Stilbenes are present in wine, varying significantly due to factors such as climate, grape variety, fungal infection (Perrone et al. 2007), UV light, metal ions

(Pussa et al. 2006) and enological methods (Gambuti et al. 2004). Resveratrol, an important stilbene (Fig. 11), is produced by vines in response to Botrytis infection and other fungal attacks (Favaron et al. 2009). Resveratrol occurs in two isomeric forms, the trans- and cis-configured isomers; light influences the cis / trans isomerization. The glucosilated forms of resveratrol are trans-piceid and cis-piceid.

The main sources of stilbenes and their health benefits are presented in Table 1.

\subsubsection{Lignans}

Lignans (Fig. 12) are a group of phenolic compounds, which occur in high concentrations in flaxseed and other seeds (Landete 2012), roots, leaves, fruits and woody parts of vascular plants (Ekiert et al. 2013) and grains (Gerstenmeyer et al. 2013). The lignans' structures are built on C6C3 units (a propylbenzene skeleton) derived from cinnamyl units. 
Six lignans (Lari, Mat, Med, Pin, Seco, Syr) have been quantified in food products: roots, leaves, seeds, fruits and woody parts of vascular plants, vegetables, non-alcoholic beverages, alcoholic beverages and cereals (Smeds et al 2007, Peñalvo et al. 2008, Bonzanini et al. 2009).

The main sources of lignans and their health benefits are presented in Table 1.

\section{Analysis of antioxidants in food}

In recent decades many methods have been developed for the analysis of antioxidants. These methods involve the evaluation of total antioxidant activity (by spectrophotometric or electrochemical methods) and the individual identification and quantification of different antioxidant substances (HPLC, GC, LC, TLC, MS, NMR, capillary electrophoresis, NIR methods). However, before quantification, extraction of the different compounds from the food matrix is required. This involves using organic solvents, supercritical fluids, microwave procedures, subcritical water extraction, high hydrostatic pressure, pulsed electric fields, ultrasonics or subcritical water.

\subsection{Extraction}

The extraction yield of antioxidant compounds from plant material is influenced mainly by the conditions under which the process of liquid-solid extraction is carried out. As each plant material has unique properties in terms of structure and composition, the behaviour of the resulting material-solvent system is unpredictable when they are combined with solvents (GonzálezMontelongo, Lobo \& González 2010).

\subsubsection{Extraction with solvents}


Solvent extraction is a separation operation which applies a solvent to extract/separate a desired component (the solute) from solid food. The separation factor for solvent extraction is the chemical equilibrium of the component between solid and solvent phases and the driving force for solvent extraction is the concentration difference of the component between the two phases. In principle, an ideal solvent should have the following desirable features: it should have a high capacity for the solute being separated into it, it should be selective, dissolving the specific component to a large extent while having a minimum capacity for the other components, it should be chemically stable (no irreversible reactions with contacting components), it should be regenerable, and it should have low viscosity for easy pumping and transportation (Campbell-Platt, 2007). In Table 2 the organic solvents used for antioxidant extraction are presented.

Anthocyanins are polar molecules, thus the most common efficient solvents used in the extractions are aqueous mixtures of acetone, methanol and ethanol (Kahkonen, Hopia, \& Heinone 2001). Among the most common methods are those which use acidified methanol or ethanol as extraction solvents (Chandrasekhar, Madhusudhan \& Raqhavarao et al. 2012, Patil et al. 2009). The acid in the solvents acts to rupture cell membranes and to release anthocyanins, however this harsh chemical treatment may break down the innate anthocyanin structure. It is therefore important to acidify the solvents with organic acids (formic or acetic acid) rather than mineral acids such as $0.1 \% \mathrm{HCl}$ (Castañeda-Ovanda et al. 2009).

The extraction of anthocyanins from red cabbage with $1 \%(\mathrm{v} / \mathrm{v}) \mathrm{HCl}$ in methanol is better than the extraction with acidified ethanol (50\%, v/v) (Chandrasekhar, Madhusudhan \& Raqhavarao 2012). Nevertheless, in the food industry ethanol is preferred due to the toxicity of methanol (Castañeda-Ovanda et al. 2009). 
An acetone-water mixture has been suggested to give a better extraction of procyanidins from grape seeds in comparison with other extractants (Yilmaz \& Toledo, 2006).

Alcoholic solvents have been commonly employed to extract phenolics from natural sources. They yield quite high levels of total extract even though they are not highly selective for phenols. In fact, ethanol, a polar solvent, effectively extracts flavonoids and their glycosides, cathecols and tannins from raw plant materials, but the solubility of these compounds can be enhanced using a mixed solvent over a limited compositional range (Castañeda-Ovanda et al. 2009).

Lycopene, a fat-soluble antioxidant, is extracted with organic solvents, such as acetone, benzene, ethanol, petroleum ether, hexane and chloroform (Kaur et al. 2008). A mixture of hexane with acetone and ethanol or methanol is often used because other components, such as diethyl ether and tetrahydrofuran, may contain peroxides that react with carotenoids (Van den Berg et al. 2000). The stability of lycopene extracts obtained with hexane/acetone or hexane/ethanol is higher than that of extracts obtained with other organic solvents, such as chloroform, methanol or dichloromethane (Kauer et al. 2008).

Alothman, Bhat \& Karim (2009) tried different types of solvents such as: $\mathrm{H}_{2} \mathrm{O} /$ methanol; $\mathrm{H}_{2} \mathrm{O}$ /ethanol and $\mathrm{H}_{2} \mathrm{O}$ /acetone $(50: 50,70: 30$ and $90: 10$, v/v) to assay the antioxidant activity (expressed using FRAP and DPPH methods) of pineapple, banana and guava. They observed that in the case of the DPPH assay the highest level of antioxidant activity was achieved with $90 \%$ acetone, while water was the worst solvent. In the case of the FRAP assay, 50\% acetone was the most suitable one, while $90 \%$ ethanol was the worst one.

\subsubsection{Extraction with supercritical fluids}


Extraction with supercritical fluids (SCF) has become increasingly popular in biomaterial processing. Unlike normal solvent extraction, supercritical fluid extractions use fluids in their supercritical states. Supercritical fluids exhibit desirable transport properties that enhance their adaptability as solvents for extraction processes (Campbell-Platt, 2007). The extraction efficiency of polar compounds with $\mathrm{CO}_{2}$ can be improved by the addition of small quantities of polar organic solvents used as modifiers. $\mathrm{CO}_{2}$ is non-toxic, non-flammable, and requires a minimum amount of solvent (5-10 ml). Extraction is fast (10-60 min), selective, requires no additional clean-up and can be carried out with small amounts of sample (Rial-Otero et al. 2007).

$\mathrm{CO}_{2}$ cannot extract compounds with high molecular weight (e.g. anthocyanins) because of its lipophilic and nonpolar nature. To eliminate these drawbacks co-solvents are used to enhance the solubility of target compounds and to increase the extraction selectivity. Another way to eliminate this drawback is the use of enhanced solvent extraction (ESE). ESE consists of using $\mathrm{CO}_{2}$, organic solvents and/or water at temperatures higher than the ambient temperature (40-200 ${ }^{\circ} \mathrm{C}$ ) and pressures between 3.3 and 20.3 MPa. The ESE technique has been used with success for the extraction of polar compounds (Adil, Yener, \& Bayindirh 2008) including anthocyanins from elderberry pomace (Seabra et al. 2008, Serra et al. 2010).

The extraction efficiency of supercritical fluids can be improved using ethanol as a modifier (Veggi, Cavalcanti \& Meireles 2011).

Lycopene extraction with supercritical $\mathrm{CO}_{2}$ could cause isomerisation and decomposition (Cadoni et al. 2000). Supercritical $\mathrm{CO}_{2}$ has been applied for the extraction of polyphenols from grapes (Ghafoor, Park \& Choi 2010, Wijngaard et al. 2012, Boussetta et al. 2012) rosemary (Visentin et al. 2012) and wine. The extraction efficiency of polyphenols from wine increases with the ethanol dose added (Wu et al. 2009). 


\subsubsection{Microwave-assisted extraction}

Microwave-assisted extraction (MAE) has become very popular in the last decade due to the reduction of extraction time and solvent used. This technique involves extraction with controlled pressure and temperature. The use of closed vessels shortens the extraction time and increases the extraction efficiency (Ballards et al. 2010). This method has been applied for the extraction of phenolic compounds from plant material (Ballards et al. 2010, Tsubaki, Sakamoto \& Azuma 2010). MAE can be used with or without the addition of any solvent.

Solvent-free microwave extraction (SFME) (Lucchesi, Chemat \& Smadja 2004) and microwave hydrodiffusion and gravity (MHG) (Abert Vian et al. 2008) are both types of solvent free MAE performed at atmospheric pressure. SFME is based on a combination of microwave heating and dry distillation which does not need any addition of solvent (Michel, Destandau \& Elfakir 2011). Microwave hydrodiffusion and gravity (MHG) is a novel, green technology, which has been used for the extraction of polyphenols from onion (Zill-e-Huma et al. 2011). The diffusion of secondary metabolites by microwaves is the result of an increase in permeability and tissue softening. During microwave extraction the mass transfer increases due to higher penetration capacity following cell disruption. MHG is an economical, efficient and environmentally-friendly extraction method; this method requires less energy and no solvent, combining microwaves and the earth's gravity at atmospheric pressure (Chemat, Abert-Vian \& Visinoni 2008, Zill-e-Huma et al. 2011).

4.1.4. Subcritical water extraction (SWE) is increasingly used in the preparation of environmental samples, and the extraction of natural products from herbs, plants and foodstuffs (Plaza et al. 2012). Subcritical water, also called pressurized (hot) water refers to water at a 
temperature between 100 and $374^{\circ} \mathrm{C}$ and a pressure which is high enough to maintain the liquid state (below the critical pressure of $22 \mathrm{MPa}$ ) (Ramos, Kristenson \& Brinkman 2002). An important feature of subcritical water is a reduction in polarity, expressed as a dielectric constant with increasing temperature.

SWE is a highly efficient method for the extraction of phenolic compounds from pomegranate (Punicagranatum L.) seed residues (He et al. 2012), anthocyanins and other phenolic compounds from dried red grape skin (Ju \& Howard, 2005) and potato peel (Singh \& Saldana, 2011) and flavanones from citrus peel (Cheigh, Chung \& Chung 2012).

4.1.5. Ultrasonics is one of the most used techniques in industry to enhance the mass transfer phenomena. The mass transfer rate is increased in ultrasonic extraction by cavitation forces, in this case the bubbles in the liquid/solid extraction can explosively collapse and generate localized pressure causing plant tissue rupture and improving the release of intracellular substances into the solvent (Knorr, Ade-Omowaye \& Heinz 2002). Ultrasonic extraction is applied in the case of anthocyanin extraction from grapes (Corrales et al. 2008), flavonoids from Prunella vulgaris L. (Zhang, Fu \& Zhang 2011) and polyphenols from orange peel (Khan et al. 2010).

4.1.6. Pulsed electric fields $(\mathrm{PEF})$ are being developed as a non-thermal emerging technology for the preservation of food. PEF enhances mass transfer rates by cell membranes improving tissue softness, influencing textural properties and the electroporation of plants. PEF increases the content of valuable components when applied to juice production and can replace the enzymatic maceration of the process (Corrales et al. 2008). PEF was applied in the case of anthocyanin extraction from grapes (Corrales et al. 2008) as well as carotenoid and phenolics (Odriozola-Serrano et al. 2009) 
4.1.7. High hydrostatic pressure (HHP). The use of HHP improves mass transfer rates increasing cell permeability as well as increasing secondary metabolite diffusion according to changes in phase transitions (Richard, 1992). During HHP extraction the liquid partially fills the air gaps present in fruit tissues. When the pressure is released subsequently, the occluded air in the pores exits causing plant cell membrane damage (Fernandez Garcia, Butz \& Tauscher 2001). HHP was applied in the case of anthocyanin extraction from grapes (Corrales et al. 2008, 2009), polyphenols and anthocyanins from red fruits (Ferrari; Maresca \& Ciccarone 2011) and anthocyanins from grape skins (Corrales et al. 2009).

4.1.8. High voltage electrical discharges (HVED) have electrical and mechanical effects on the product caused by shock waves. This technique introduces energy directly into an aqueous solution through a plasma channel formed by a high-current/high-voltage electrical discharge between two submerged electrodes. The phenomen of HVED is based on the electrical breakdown in water. Water vapor bubbles that are initially present in water formed due to local heating are involved in this phenomenon and accelerate the process. If the electrical field is intense enough, the avalanche of electrons becomes a starting point of streamer propagation from the high voltage needle electrode to the grounded one. The electrical breakdown is accompanied by a number of secondary phenomena (high-amplitude pressure shock waves, bubble cavitation, creation of liquid turbulence, etc.). These secondary phenomena cause particle fragmentation and cell structure damage (Bousetta et al. 2013). This technique includes a large range of current $\left(10^{3}-10^{4} \mathrm{~A}\right)$, voltage $\left(10^{3}-10^{4} \mathrm{~V}\right)$ and frequency $\left(10^{-2}-10^{-3} \mathrm{~Hz}\right)$ (Chang et al. 1998). The HVED method requires short treatment times (a few ms) and low energy consumption (10-50 kJ/kg) (Gros, Lanoiselle \& Vorobiev, 2003). The temperature elevation after treatment is low $\left(<5^{\circ} \mathrm{C}\right)$. HVED was applied in the case of oil extraction from linseed (Gros, Lanoiselle \& Vorobiev, 2003), 
polyphenols from wine by-products (Boussetta, Lanoiselle, Bedel-Cloutour \& Vorobiev, 2009, Bousseta et al. 2009), grape pomace (Boussetta et al. 2011) and grape seed (Liu, Vorobied, Savoire \& Lanoiselle 2011).

4.1.9. Enzyme-assisted extraction (EAE) is an efficient procedure to enhance the release and recovery of bioactive compounds from plants and algae. Enzymes can effectively catalyze the degradation of vegetable cell walls, favoring the release of bioactive components contained inside the cells. The primary cell wall of plants is mainly composed of cellulose, hemicelluloses (xyloglucans), pectin and proteins (Jordan et al. 2012). Besides, phenolic compounds have been reported to be linked to cell wall polysaccharides by hydrophobic interactions and hydrogen bonds. Therefore, cellulases, hemicelullases, pectinases as well as other enzymes can be used to disrupt the cell wall structure, break down complex interior storage materials, thereby facilitating the release of intracellular bioactive compounds (Pinelo, Zonrnoza \& Meyer, 2008, Wang et al. 2010). EAE has been applied for the extraction of antioxidant compounds from lemon balm (Melissa officinalis) (Miron, Herrero \& Ibanez, 2013), red algae (Palmaria palmate) (Wang et al. 2010) Agaricus blazei Murrilli (Jia et al. 2013), alfalfa (Wang, Dong, Tong 2013) and pumpkin (Cucurbita moschata) (Wu, Zhu, Diao \& Wang 2014).

The advantages and disadvantages of each type of extraction are presented in Table 3.

\subsection{Isolation and purification}

The classical methods used for the isolation of antioxidants from complex extracts are timeconsuming, labor intensive, expensive and sometimes have many errors in isolation and purification due to dilution effects or decomposition effects on antioxidants (Dai et al. 2013). HPLC is a good method for antioxidant isolation and purification based on-line post-column free 
radical assays (Nuengchamnong, Krittaship, \& Ingkaninan, 2011); however this method needs technical skills, special equipment and has lower resolution and sensitivity (Li et al. 2012). A suitable method for isolation and purification might be high-speed counter-current chromatography (HSCCC). HSCCC is a liquid-liquid partition chromatography based on two immiscible phases without support matrix, a low risk of sample denaturation, no irreversible adsorption, total sample recovery, large load capacity and low cost (Dai et al., 2013).

HSCCC was applied with success for many bioactive compounds (e.g. phenolics) from natural products (Dai et al. 2013, Li et al. 2013). Trabelsi et al. (2012) purified phenolic compounds from Limoniastrum guyonianum using a preparative HPLC equipped with a 2-way binary highpressure gradient pump.

Other methods used for antioxidant isolation and purification are: ethyl $t$-butyl ether fraction of extracts, butanol fraction (involves silica gel column separation) (Pukalskas et al. 2012), ultrafiltration, gel filtration chromatography and reversed-phase high-performance liquid chromatography (RP-HPLC) (Chen et al. 2012), diethylaminoethyl-Cellulose (DEAE-C) (AlSheraji et al. 2012), ion exchange chromatography (Lapsongphon \& Yongsawatdigul, 2013).

Macroporous adsoption resins were used in the purification of bioactive constituents from natural extracts due to their high efficiency (Jia \& Lu, 2008). The macroporous adsorption resins exhibit higher adsorption capacity not only because of their similar polarity with the target compounds, but also because of their surface area and larger average pore diameter. Macroporous resins (MARs) are durable polar, non-polar or slightly hydrophilic polymers with high adsorption capacity. Compared to the conventional matrices, MARs have some advantages, such as mechanical strength, diverse structures, good performance, low costs and environmental friendliness (Sun et al. 2013). This method is time-consuming, laborious and requires large 
volumes of solvents (Ma et al. 2013). Phenolics possessing benzene rings and hydrogen groups, could be adsorbed by polar or weak-polar resins with proper surface area and average pore diameter (Lin et al. 2012). The macroporous resins have been used for the purification and separation of bioactive substances from trollflowers (Sun et al. 2013), brown seaweed Ecklonia cava (Kim et al. 2014), Glycyrrhiza glabra L. leaf (Dong et al. 2015) and Dalbergia odorifera T. Chen leaves (Ma et al. 2013). The isolation and purification of Grifola fandosa antioxidant was reported by Chen et al. (2012). They used an anion-exchange chromatography for isolation reaching a total yield of $3.13 \%$. The elution peaks obtained were collected, concentrated and purified by a gel filtration chromatography, reaching recovery levels between 21.5 and $33.3 \%$.

The anthocyanins can be isolated with the following procedure: extraction ( $80 \%$ methanol containing sodium sulphate or acetone-water solution, petroleum ether (Chai et al. 2012) followed by purification (using an Amberlite XAD-16 ion exchange gel or macroporous resins (Wiczkowski, Szawara-Nowak \& Topolska, 2013, Zhang et al. 2013) and initial separation of anthocyanins on ion-exchange gel. The isolation was made up on a C18 semi-preparative column (Wiczkowski, Szawara-Nowak \& Topolska, 2013).

\subsection{Evaluation of total antioxidant activity}

\subsubsection{In vitro methods}

DPPH (1,1-diphenyl-2-picrylhydrazyl) scavenging activity

The DPPH assay is based on the reduction by antioxidants of the purple DPPH radical to the corresponding pale yellow compound, which is measured colorimetrically at $520 \mathrm{~nm}$ (Molyneux, 2004). It is widely used to easily and accurately measure the antioxidant capacity of fruit and vegetable juices or extracts (Sharma \& Bhat, 2009). The DPPH assay is relatively simple 
and stable and is available commercially with a high degree of purity. The percentage of inhibition of DPPH within the assay time will reflect the antioxidant capacity of the extract assessed. The assay time would vary from 10-20 min up to about 6 h (Gil, Ferreres \& 1999). Drawbacks associated with the DPPH assay are that other compounds may absorb at $515 \mathrm{~nm}$ and there may be a steric hindrance for high molecular weight molecules (Pérez-Jiménez et al. 2008). In the case of herbs the DPPH assay is correlated with phenolic content (Moraes-de-Souza et al. 2008).

DPPH has been applied to quantify the antioxidant activity of beer (Tafulo et al. 2010), crisps (Zieliński, Zelińska \& Kostyra 2012), herbal extracts (Mrazek et al. 2012), mulberry fruit (Lou et al. 2012), tomatoes (Kaur et al. 2013), propolis (Potkonjak et al. 2012), honey (Oroian 2012), wine and grape juice (Pinho et al. 2012), onions (Lu et al. 2011), vegetable juice (WoottonBeard, Moran \& Ryan 2011), vegetables (Li et al. 2012) and olives (Fernandez-Orozco et al. 2011).

On-line DPPH-HPLC (High Performance Liquid Chromatography) methods could be used for a rapid screening of antioxidants from complex mixtures, particularly for natural products with a minimum of sample preparation (Dai et al. 2013). The DPPH-HPLC method was been developed for the determination of DPPH scavenging activity, due to the drawbacks of the DPPH assay. The DPPH assay is a typical off-line detection method, where the antioxidant activity is measured colorimetrically However, the DPPH and anthocyanins showed strong absorption at 500-550 nm and so the weak changes in DPPH absorbance could not be observed and quantified (Sun et al. 2012).

The on-line DPPH-HPLC method involves the post-column extract reaction with DPPH according to the colorimetric assay (at $517 \mathrm{~nm}$ ) and then the mixture is passed to the HPLC detection (Zhang et al. 2013). The peak areas of compounds with potential antioxidant activities 
will be reduced or disappear in the HPLC chromatogram after their reaction with DPPH, and for those without antioxidant activities, the peak areas have almost no change (Dai et al. 2013).

Free radical scavenging activity can be evaluated by comparison with the water-soluble synthetic vitamin E derivate 6-hydroxy-2,5,7,8-tetramethylchroman-2-carboxylic acid (Trolox). This method permits a rapid, selective and relatively detection of free radicals in complex mixtures and a quantitative analysis of individual antioxidants in complex mixtures (Zhang et al. 2013). The On-line HPLC with DPPH radical scavenging assay has disadvantages that these targets of antioxidative activity could not be purified for the identification and/or evaluation of unknown compounds by NMR, in vivo, and in vitro assays (Inoue et al. 2012).

The on-line DPPH-HPLC method has been applied for antioxidant screening from rabbit eye blueberry (Sun et al. 2012), Eucommia ulmoides Olive leaves (Dai et al. 2013), peanut shells (Qiu et al. 2012), Teucrium polium (Goulas et al. 2012), pomegranate (Romani, Campo \& Pinelli 2012), Pueraria lobata (Shi et al. 2012), Selaginella sinensis (Zhang, Fu \& Zhang 2011), tea (Zhang et al. 2013), fruit wine (Nuengchamnong \& Ingkaninan 2010), red cabbage (Inoue et al. 2012) and koji (Giri et al. 2012). For the identification of the antioxidant compound HPLC-DPPH coupled with HSCCC has been used (Zhang et al. 2011, Dai et al. 2013, Inoue et al. 2012, Shi et al. 2012), TOF/MS (Qiu et al. 2012), SPE-NMR (Goulas et al. 2013), DAD (Zhang et al. 2013), MS (Nuengchamnong \& Ingkaninan 2010).

Determination of Trolox equivalent antioxidant capacity (TEAC)

The TEAC assay is a simple and much used technique for measuring the antioxidant capacity (Gan et al. 2010) of hydrophilic and lipophilic components from plant samples. TEAC is based on the inhibition of the absorbance of the radical cation of 2,2'-azinobis(3ethylbenzothiazoline 6-sulfonate) (ABTS) by reductants. They present absorption spectrum 
maxima at 660,734 and $820 \mathrm{~nm}$ respectively. The interaction between ferrylmyoglobin radicals (generated by the activation of metmyoglobin with $\mathrm{H}_{2} \mathrm{O}_{2}$ ) and ABTS forms the ABTS radical cation. The TEAC assay measures the ability of a compound to reduce the ABTS radicals, although the compound under analysis can also reduce ferrylmyoglobin radicals (Cadenas \& Parker, 2001). The advantages of the ABTS method are: inexpensive, fast, easy to use and $\mathrm{pH}$ stable (hence it can be used to study the effect of $\mathrm{pH}$ on activity), and the disadvantages are: it is not standardized (so it is hard to compare values across laboratories), and it generates free radicals that are not stable for long periods of time (Pérez-Jiménez et al. 2008, Zulueta et al. 2009).

TEAC has been applied for quantifying the antioxidant activity of: coffee (Parras et al. 2007), beer (Tafulo et al. 2010), commercial water (Moreira et al. 2012), crisps (Zieliński et al. 2012), mulberry fruit (Lou et al. 2012), tomatoes (Kaur et al. 2013), apples (Ceymann et al. 2012), onions ( $\mathrm{Lu}$ et al. 2011), cereal grains (Deng et al. 2012) and bilberries (Betz et al. 2012).

\section{Determination of ferric reducing/antioxidant power (FRAP)}

The FRAP assay is a simple method which has been applied in the last decades for the evaluation of the antioxidant capacity of plant materials. It is based on the ability of antioxidants to reduce ferric ions $\left(\mathrm{Fe}^{3+}\right)$ to ferrous ions $\left(\mathrm{Fe}^{2+}\right)$ (Benzie \& Strain, 1996). The FRAP reagent is 2 , 4, 6-tris (1-pyridyl)-5-triazine (TPTZ) and it is prepared in a buffer of sodium acetate at $\mathrm{pH} 3.6$. The colour of the reduced form of iron in TPTZ is a blue product (ferrous-TPTZ complex) whose absorbance can be read at $593 \mathrm{~nm}$. The main drawback is that at $593 \mathrm{~nm}$ other compounds may be absorbed and the assay is performed at a non-physiological pH (Pérez-Jiménez et al. 2008).

FRAP has been applied to quantify the antioxidant activity of beer (Tafulo et al. 2010), commercial water (Moreira et al. 2012), tomatoes (Kaur et al. 2013), apples (Ceymann et al. 2012), 
onions (Lu et al. 2011), grains (Deng et al. 2012), vegetable juices (Wootton-Beard, Moran \& Ryan 2011), tea (Martins et al. 2013) and vegetables (Li et al. 2012).

\section{Oxygen radical absorbance capacity $(O R A C)$}

ORAC is an assay widely used for measuring the total antioxidant activity of supplements, and biological and food samples (Prior et al. 2003). The radical initiator component of this assay 2, 2'-azobis (2 amidinopropane) dihydrochloride (AAPH), is a water-soluble free radical initiator. It spontaneously decomposes at $37{ }^{\circ} \mathrm{C}$ to carbon-centred radicals which react with oxygen to generate peroxyl radicals (Prior, Stahl \& Rock 2003). This method measures the ability of the antioxidants present in a sample to protect the protein form oxidative damage. Advantages of ORAC are: it allows data comparison between laboratories; it integrates both degree and time of antioxidant reaction and uses biologically relevant free radicals. Disadvantages of ORAC are: it is an expensive method due to the equipment required, it is a $\mathrm{pH}$ sensitive method, data variability can be large between laboratories; the quantification of results requires a lot of time (Zulueta, Esteve \& Frigola 2009), the method cannot be applied for kinetic studies because the reaction kinetics may vary depending on the concentration of the antioxidant; proteins may interfere, and it measures the ability of antioxidants to scavenge peroxyl radicals (Pérez-Jiménez et al. 2008).

ORAC has been applied to quantify the antioxidant activity of beer (Tafulo et al. 2010), commercial water (Moreira et al. 2012), vegetables (Č́íž et al. 2010; Li et al. 2012), cauliflower (Cabello-Hurtado, Gicquel \& Esnault 2012) and tea extracts (Macedo et al. 2011).

\section{Hydroxyl Radical-Scavenging Capacity Assay (HRSCA)}


This test measures the ability of the antioxidant samples to compete with a molecular probe (fluorescein), and scavenge the hydroxyl radical generated by the Fenton-like $\mathrm{Fe}^{3+} / \mathrm{H}_{2} \mathrm{O}_{2}$ solutions. Fluorescein reacts with hydroxyl radicals present in the antioxidant sample and forms a nonfluorescent product, which can be monitored by measuring the fluorescence reduction of fluorescein. The area under the sample reaction kinetic curve is used to evaluate the antioxidant capacity (Yu, 2008).

Advantages of hydroxyl radical-scavenging capacity assay: this method measures scavenging capacity against physiologically important free radicals, it involves a radical generating system which was validated using ESR spin trapping techniques and the solvent was tested for its compatibility using ESR spin trapping techniques (Yu, 2008).

Disadvantages: the addition of $\mathrm{FeCl}_{3}$ and $\mathrm{H}_{2} \mathrm{O}_{2}$ solutions for starting the generation of hydroxyl radicals is the most critical step in this method, so the method requires a skilled operator, the kinetic assays are time consuming, expensive devices are necessary for the analysis of a large amounts of samples (e.g. microplate readers), it is only compatible with water and acetone and is not appropriate for the lipophilic compounds (Yu, 2008).

The method has been applied for quantifying the antioxidant activity of: coffee (Parras et al. 2007), white radish (Kuda et al. 2010), saba-narezushi (Kanno et al. 2012) and red maple extract (Royer, Diouf \& Stevanovic 2011).

\subsubsection{In vivo methods}

The in vivo action of antioxidants is due to the inhibition generation of the reactive oxygen species or by direct scavenging of free radicals (Aruoma 2003). In the case of in vivo methods, the antioxidants should be absorbed, transported, distributed and retained properly in the biological 
fluids, cells and tissues. The in vivo methods involve testing the antioxidant administration to animals at a specified dosage regimen. After a period of time, the animal blood or tissues are used for the assay. During the animal treatment for the antioxidant capacity measurement many transformations could occur (e.g. biotransformation during enzymatic conjugation), and for these reasons the experiments should be treated with caution (Niki 2010).

The in vivo antioxidant capacity may be measured using biological fluids and tissues (erythrocytes, urine, plasma, cerebrospinal fluids, saliva or tear) from humans or animals (Liu et al. 2013).

The most used methods for the evaluation of antioxidant activity in vivo are presented below.

\section{Total radical-trapping parameter (TRAP)}

Wayner et al. (1985 a,b) developed the total radical trapping parameters assay (TRAP) for measuring the total antioxidant capacity in plasma and serum. This technique has been applied with success in recent years to quantify the antioxidant activity of procyanidins (from Vitis vinifera seeds) in plasma (Simonetti et al. 2002).

\section{Reduced glutathione (GSH) estimation}

The method was proposed by Ellaman (1959) for the determination of antioxidant activity. The reduced glutathione is an intra-cellular reductant which plays an important role in catalysis, metabolism and transport (Alam, Bristin \& Rafiquzzaman 2013). The sample is treated with 20\% trichloroacetic acid and Ellman's reagent (5,5'-dithiobis-2-nitrobenzoic acid). The resulting solution is measured at $412 \mathrm{~nm}$ against a blank. GSH was used to evaluate the influence on the antioxidant effects of pomegranate juice (Matthaiou et al. 2014) in human blood. 


\section{Superoxide dismutase (SOD)}

Superoxide dismutase (SOD) is based on its ability to inhibit oxidation of oxyamine by the xanthine-xanthine oxidase system. The SODs remove $\mathrm{O}_{2}{ }^{--}$by greatly accelerating its conversion to $\mathrm{H}_{2} \mathrm{O}_{2}$. The SOD measurement unit $(\mathrm{U})$ is defined as the amount that reduces the absorbance at $550 \mathrm{~nm}$ by $50 \%$ after reacting for $10 \mathrm{~min}$. Oyanagui (1984) expressed the SOD unit in U/mg protein.

The models used for measuring the SOD of some plants extracts were: mice blood liver serum (for high molecular weight persimmon tannin (Tian et al. 2012)), mice liver (for green tea (Camelliasinensis, Theaceae) (Tsai et al. 2013) and wine (Gris et al. 2013)), mice liver, blood and heart (for white button mushrooms (Agaricus bisporus) (Liu et al. 2013)) and white rabbit red blood cells (for white rice, brown rice and germinated brown rice (Esa et al. 2013)).

\section{Glutathione peroxidase (GSH-Px)}

Yang et al. (2010) defined GSH-Px as the rate of enzyme-catalysed oxidation of GSH per minute. GSH-PX unit (U) is defined as a decrease of $1.0 \mu \mathrm{M}$ glutathione per $5 \mathrm{~min}$ at $37^{\circ} \mathrm{C}$, and data are expressed as $\mathrm{U} / \mathrm{mg}$ protein for liver tissue and $\mathrm{U} / \mathrm{ml}$ for serum.

The models used for measuring the GSH-Px of some plants extracts were: mice blood liver serum (for high molecular weight persimmon tannin (Tian et al. 2012)), mice liver (for green tea (Camelliasinensis, Theaceae) (Tsai et al. 2013) and wine (Gris et al. 2013)), mice liver, blood and heart (for white button mushrooms (Agaricus bisporus) (Liu et al. 2013)) and white rabbit red blood cells (for white rice, brown rice and germinated brown rice (Esa et al. 2013)).

Catalase (CAT) 
In 1984, Aebi developed the catalase activity method using erythrocyte lysate. This activity measures the decrease in $\mathrm{H}_{2} \mathrm{O}_{2}$ in a freshly prepared $10 \mathrm{mM}$ hydrogen peroxide solution at 240 $\mathrm{nm}$, and is expressed in $\mathrm{mmol} \cdot \mathrm{min}^{-1} \mathrm{mg}$ protein ${ }^{-1}$ and $\varepsilon=40 \mathrm{~L} \cdot \mathrm{mmoll}^{-1} \cdot \mathrm{cm}^{-1}$ (Gris et al. 2013)

The models used for measuring the CAT of some plant extracts were: mice liver (for green tea (Camelliasinensis, Theaceae) (Tsai et al. 2013)), mice liver, blood and heart (for white button mushrooms (Agaricus bisporus) (Liu et al. 2013)) and rat liver and kidneys (for Toona sinensis Roem leaf extracts (Yu et al. 2012)).

\section{Lipid peroxidation (LP)}

The lipid peroxidation method developed by Hsu et al. (2008) involves measuring the concentration of thiobarbituric acid reactive substances (TBARS) in the liver. The index of lipid peroxidation is given by the amount of TBARS formed by their reaction with thiobarbituric acid (TBA). The compound obtained is measured at $535 \mathrm{~nm}$ (Tsai et al. 2013).

The models used for measuring the LP of some plant extracts were: mice blood liver serum (for high molecular weight persimmon tannin (Tian et al. 2012)), mice liver (for green tea (Camelliasinensis, Theaceae) (Tsai et al. 2013)), white rabbit red blood cells (for white rice, brown rice and germinated brown rice (Esa et al. 2013)) and liposomal system (for cocoa extract (Locatelli et al. 2013).

\subsubsection{Electrochemical methods}

\subsubsection{Voltammetric procedures}

The cyclic voltammetry procedure is an affordable, rapid and sensitive enough method for the determination of antioxidants. Cyclic voltammetry involves three electrodes: the working 
electrode (e.g., glassy carbon), the reference electrode $(\mathrm{Ag}-\mathrm{AgCl})$, and the auxiliary electrode (platinum wire). The working electrode is subjected to a constant potential rate of $100 \mathrm{mV} / \mathrm{s}$ and records the evolution curve named cyclic voltammogram. The two parameters of reducing power of a sample are: the peak potential $\left[\mathrm{E}_{\mathrm{p}(\mathrm{a})}\right]$, which may be correlated with individual compounds, and the anodic current $\left(\mathrm{I}_{\mathrm{p}(\mathrm{a})}\right)$, which may be correlated with the antioxidant concentration (Cadenas \& Packer, 2001).

Cyclic voltammetry proved to be a useful technique for the rapid determination of antioxidant capacity in fruit tea beverages. Piljac-Žegarec et al. (2010) observed that the high degree of positive correlation with the other antioxidant capacity measures indicate that the results derived from cyclic voltammetry are reliable and comparable to the results of commonly used methods for antioxidant capacity.

Cyclic voltammetry has been applied with success in the case of green pepper (Chatterjee et al. 2007), green, oolong and black teas (Kilmartin \& Hsu, 2003), wine (Kilmartin, Honglei \& Waterhouse 2002), fruit juice (Piljac-Žegarec et al. 2009), algae (Campanella, Martini \& Tomassetti 2005), wild plants (Barros et al. 2011a) and seaweeds (Keyrouz et al. 2011).

Differential pulse voltammetry has been applied to measure the antioxidant activity of wine (Šeruga, Novak \& Jakobek 2011, Aguirre et al. 2010), raspberries (Aguirre et al. 2010) and wild plants (Barros et al. 2011a).

\subsubsection{Bionsensors}

Campanella et al. (2004) developed a superoxide dismutase (SOD) biosensor for the determination of the total and natural antioxidant capacity of red and white wines. The biosensor was obtained by coupling a transducer (an amperometric electrode for hydrogen peroxide, with a platinum anode maintained at a constant potential of $+650 \mathrm{mV}$ with respect to an $\mathrm{Ag} / \mathrm{AgCl} / \mathrm{Cl}^{-}$ 
cathode) and the superoxide dismutase enzyme immobilised in a gel-like kappa-carrageenan membrane. They observed that the correlation between total antioxidant activity measured by various spectroscopic methods for white and red wines, respectively, has a relatively strong correlation with the bionsensor method.

The SOD biosensor method is a valid method for measuring the capacity of algae (Campanella, Martini \& Tomassetti 2005). This method permits the measurement of the antioxidant capacity in the case of both cultivated and powdered algae, and also when the algae sample is tested in its whole form or after homogenization and centrifugation (Campanella, Martini \& Tomassetti 2005).

The purine-based biosensor (adenine or guanine) for antioxidant activity is based on the interaction of adenine or guanine immobilized on the glassy carbon electrode (GCE) surface with the hydroxyl radical. Vitamin $\mathrm{C}$ presents the highest antioxidant activity values and seems to be the most sensitive standard antioxidant. The purine-based biosensor is disposable, and requires very easy, rapid, reproducible preparation and can be combined with portable equipment (Barroso, Delerue-Matos \& Oliveira 2012).

Han et al. (2012) developed a novel amperometric biosensor based on immobilizing tyrosinase on the surface of a Mg-Al- $\mathrm{CO}_{3} \mathrm{HTLc}$ modified electrode for the detection of polyphenols. The fabricated biosensor showed a low detection limit, satisfactory linear concentration range, excellent stability, high reproducibility and effective application to real samples (different type of tea).

Gil \& Rebelo (2010) have developed a laccase-based biosensor to evaluate the antioxidant activity of wine. They observed a good correlation between the antioxidant properties determined using the ABTS assay and the bioelectrochemical polyphenol index obtained at $\mathrm{pH} 3.5$ with the 
biosensor, taking caffeic acid as reference solution. The immobilization of the enzyme on the derivated polyethersulfone membranes is rapid.

\section{Chemiluminescent methods}

Chemilumiscences (CL) is a sensitive and fast method for screening antioxidant activity. A suitable reagent for $\mathrm{CL}$ is luminol, due to its ability to scavenge the free radicals involved in the sequence leading to an excited electron (3-aminophtalatedianion (3-APA $\left.{ }^{*}\right)$, which emits light on return to its ground state (Barni et al. 2007).

Nalawajko-Sieliwoniuk et al. (2008) reported a new flow injection analysis-CL detection method useful for the detection and quantification of phenolic compounds (6'-caffeoylerigeroside and caffeic acid) from Erigeron acris L. extracts based on the phenolic compound-inhibited luminol- $\mathrm{I}_{2} \mathrm{CL}$ in a sodium hydroxide medium. CL-detection is advantageous due to its high sensitivity in comparison with the spectrophotometric assays (DPPH), moreover, the luminol- $\mathrm{I}_{2}$ detection system is simple and based on stable and easy-to-handle reagents.

\section{Electron spin resonance}

Electron spin resonance (ESR) also called Electron Paramagnetic Resonance (EPR) spectroscopy is the most comprehensive technique for detecting and monitoring processes involving radicals. ESR spectroscopy provides both qualitative and quantitative information about paramagnetic species having one or more unpaired electrons. Since hydroxyl radicals $(\mathrm{OH})$ have a very short life-time, spin-trapping techniques with DMPO (5,5-dimethyl-1-pyrroline-1-oxide) are being used for its detection (Elia, Azoulay \& Zeiri, 2012). This method is the only one that detects free radicals involved in autoxidation (Carocho \& Ferreira, 2013).

The identity of the radical can be deduced from the obtained ESR spectrum, since the hyperfine coupling pattern and hyperfine coupling constants are characteristic for the different 
adducts of trapped radical and spin traps. Moreover, the intensity of the ESR signal provides an estimate of the amount of radicals formed under various conditions (Hougaard et al. 2013).

Ludwig et al. (2012), measured the antioxidant activity of coffee using two stabilized radicals: potassium nitrosodisulfonate (Fremy's salt) and 2,2,6,6-tetramethyl-1-piperidin-1-oxyl (TEMPO). Mainly phenolic compounds can be detected when Fremy's salt is used as the stabilized radical, whereas TEMPO is mainly scavenged by Maillard reaction products (MRP), such as melanoidins. The results obtained with ESR spectroscopy showed that Fremy's salt scavenging capacity was almost four times higher than TEMPO (Ludwig et al. 2012).

Kohri et al. (2009) developed an ORAC-electron spin resonance (ESR) assay using a spintrapping method for the determination of the 2,2-Azobis (2-anidinopropane) dihydrochloride (AAPH) - derived free radical. The ORAC-ESR assay is based on the competitive reaction between spin-trapping of the 2,2-Azobis (2-anidinopropane) dihydrochloride -derived free radical, mainly $\mathrm{RO}$, and its elimination by particular substrate.

The ORAC-ESR assay, being based on the competitive elimination of the alkoxyl radical by substrate and spin trap, is far superior to the ORAC-FL assay and should yield the accurate ORAC values. The reaction scheme of the AAPH decomposition follows three steps: (1) the formation of an alkyl radical (Ra) by the UV irradiation of AAPH, (2) transfer of the alkyl radical to the peroxyl radical ( $\mathrm{RaOO}$ ) with $\mathrm{O}_{2}$, and (3) decomposition of the peroxyl radical to an alkoxyl radical $\left.(\mathrm{RaO})\left[\mathrm{Ra}=\mathrm{C}\left(\mathrm{CH}_{3}\right)_{2}-\mathrm{C}^{+}{ }^{+} \mathrm{NH}_{2} \mathrm{Cl}^{-}\right) \mathrm{NH}_{2}\right]$ (Nakajima et al. 2012a). This assay has very good reproducibility, and is conducted under stoichiometric experimental conditions (Nakajima et al. 2012b). 
The ESR method was applied for measuring antioxidant activity of coffee (Ludwig et al. 2012), aqueous and aroma extracts of squid miso prepared with Aspergillus oryzae-inoculated koji (Giri et al. 2011) and fermented fish paste (Giri, Nasu \& Ohshima, 2012).

\subsection{Methods for the determination of the different compounds in the antioxidant}

\section{fraction.}

\subsubsection{Chromatographic methods}

Due to its precision and versatility, High Performance Liquid Chromatography (HPLC) is used to analyse carotenoids and phenolic compounds (Parejo et al. 2004). In general, reversedphase $\mathrm{C} 18$ columns are used. The mobile phase consists of a two solvent system containing a polar organic solvent (methanol or acetonitrile) and acidified water. A UV-VIS and PDA (Photodiode array) detectors are normally coupled to HPLC for the analysis of carotenoids and phenolic compounds (Irakli et al. 2012, Luthria 2012, Šeruga, Novak \& Jakobek 2011, Zhang et al. 2013). Some procedures for identifying and quantifying some classes of antioxidants using HPLC are presented in Table 4.

HPLC is applied to detect carotenoids due to its high accuracy. For the determination of lycopene and $\beta$-carotene from food products, the samples should be extracted with a solvent mixture (hexane/acetone/ethanol $(50: 25: 25 \mathrm{v} / \mathrm{v} / \mathrm{v}))$, followed by evaporation of the hexane layer and dissolution in tetrahydrofuran/ acetonitrile/ methanol $(15: 30: 55 \mathrm{v} / \mathrm{v} / \mathrm{v})$. The solution must be injected in a C18 column, using a mobile phase composed of methanol/acetonitrile $(90: 10 \mathrm{v} / \mathrm{v})+$ $9 \mu \mathrm{M}$ trietanolamine, at a flow rate of $0.9 \mathrm{ml} / \mathrm{min}$ with the VIS detection at $475 \mathrm{~nm}$. This simple method provides reliable results using one-step direct extraction and short time (10 min) for the 
identification and quantification of $\beta$-carotene and lycopene (Olives Barba et al. 2006). Reversedphase HPLC (RP-HPLC) has been used for identification and quantification of tocopherols in several types of Amazonian fruit (Rodrigues, Darnet \& Silva 2010) and Brazilian fruit (Costa et al. 2010). The HPLC-DAD PDA has been used for the detection of stilbenes in Sicilian pistachio (Grippi et al. 2008).

Silva et al. (2011) proposed a normal-phase HPLC method for the analysis of tocopherols, carotenes and tocotrienols using a Photo Diode Array (PDA) detector at $292 \mathrm{~nm}$ (tocols) and 455 $\mathrm{nm}$ ( $\beta$-carotene) and using a fluorescence detector set at an excitation wavelength of $290 \mathrm{~nm}$ and emission wavelength of $330 \mathrm{~nm}$ respectively for vegetable oils.

One of the disadvantages of the HPLC method is the detection limit and sensitivity in complex matrices, such as crude plant extracts. Thus, an initial pre-concentration and purification of polyphenols from complex matrix is crucial prior to the instrumental analysis by HPLC. The recovery of polyphenols using polymeric resins is approved for food processing by the Food and Drug Administration and the council of Europe (Scordino et al. 2003). Gu et al. (2008) developed a method which involves macroporous adsorption resin (AB-8 macroporous resin) combined with ultra-filtration; this method was successfully employed to isolate and purify high molecular weight and low molecular weight phenolic compounds from crude extracts of persimmon.

Stilbene glycoside can be purified using open column chromatography packed with polycaprolactam; the column should be eluted stepwise with 5 times the volume of the column, for each of the four different concentrations of aqueous ethanol solutions $(10 \%, 20 \%, 30 \%$ and $40 \%$ ), and collected into four fractions. The fractions collected with $20 \%$ and $30 \%$ aqueousethanol solutions were combined and subjected again to an open $\mathrm{CC}$ column packed with polycaprolactam (Lv et al. 2007). 
The absorption of flavonoids and phenolic acids on different resins has been studied (Escriche et al. 2013). Ginger polyphenol adsorption has been studied using an anion exchange resin, AmberliteIR-400 (Data et al. 2011).

Thin-layer chromatography (TLC) is a good method for screening plant extracts for the presence of antioxidants (Waksmundza-Hajnos et al. 2008). TLC is a simple, inexpensive technique which is particularly suitable for analysing a large number of samples (Simões-Pirest et al. 2009). TLC has been applied for the detection of lignin in Oriental medicinal plants (Slanina \& Glatz 2004). In some cases, the fractions analysed using TLC may be identified by HPLC-MS or GC-MS. All lignans absorb UV light and for this reason they can be detected at $254 \mathrm{~nm}$ (Willför et al. 2005).

Gas chromatography (GC) is a good method for the identification of lignans due to its excellent resolution, although it requires the derivatisation of the compounds. This derivatisation leads to an increase in the thermal stability of lignans and enhances the detection selectivity. One group of lignans (podophyllotoxintypelignans), which does not have free hydroxyl groups does not need derivatisation for identification (Willför et al. 2006). Bonzanini et al. (2009) reported the presence of six lignans in Punicagranatum L fruit endocarp, pulp, seeds, wood knots and commercial juices.

HSCCC is a support-free liquid-liquid chromatographic technique, which allows complete recovery of the sample and is suitable for separations in large quantities (Cheng et al. 2012). HSCCC is used for the separation and isolation of tannins (Shi et al. 2008), flavonoids (Yuan et al. 2009, Liang et al. 2011) and anthocyanins (Inoue et al. 2012). 
Mass spectrometry has a very important role for research and quality control, and its analytical power is relevant for structural studies on aroma and polyphenolic compounds (Willoughby, Sheehan \& Mitrovich 2002).

Liquid Chromatography-Mass Spectrometry (LC-MS) techniques are nowadays the best analytical approach to study polyphenols in grape extracts and wine, and are the most effective tool in the study of the structure of anthocyanins. LC-MS allows the characterization of complex structures of grape polyphenols, such as procyanidins, proanthocyanidins, prodelphinidins, and tannins, and provides experimental evidence for structures that were previously only hypothesized (Flamini, 2003). LC-MS/MS has been applied for the identification and quantification of ferulic, caffeic, acid and syringic acid, quercetin, pyrogallol, $\alpha$-tocopherol, vanillin, $p$-coumaric, $p$ hydroxybenzoic, ascorbic and gallic acid in cherry stems (Cerasusavium L) (Bursal et al. 2013). Jaitz et al. (2010) have quantified gallic acid, caffeic acid, catechin, epicatehin, cis $p$-coumaric acid, trans p-coumaric acid, myricetin, cis-resveratrol, trans-resveratrol and quercitin using LCMS/MS in red wine, obtaining excellent detention limits.

HPLC-MS/MS is used for the identification and quantification of minor components at $\mathrm{mg} / \mathrm{kg}$ and $\mu \mathrm{g} / \mathrm{kg}$ levels (Zhang, Rose \& Trenerry 2009). HPLC-MS/MS has been used for the determination and quantification of vitamin A and E (Plozza, Trenerry \& Caridi 2012), $\beta$-carotene (Plozza, Trenerry \& Caridi 2012) and phenolic profile (Perestrelo et al. 2012).

Mass spectrometry coupled to gas chromatography (GC-MS) is a powerful method used to separate, identify and quantify cis- and trans- resveratrol in red wine (Cai et al. 2009). RodríguezCabo, Rodríguez \& Cela (2012) have developed a method for the identification of pterostilbene, resveratrol and piceatannol from wine using GC-MS. 
High Performance Liquid Chromatography - electrospray tandem mass spectrometry (HPLC-ESI-MS) is a versatile technique used recently for individual antioxidant analysis. Chai et al. (2012), used HPLC-ESI-MS for the identification of condensed tannins from leaf, fruit and stem bark of Delonix regia, these compounds were identified by degradation of tannins using hydrolysis in the presence of benzyl mercaptan. Stalmach et al. (2011) used HPLC-ESI for identification of anthocyanins, flavan-3-ols, flavonols, hydroxycinnamic acids, hydroxybenzoic acids, and stilbenes in grape juice.

\subsubsection{Capillary electrophoresis}

Capillary electrophoresis (CE) methods, much used in recent years (Lee, Boyce \& Breadmore 2010), are suitable for the analysis of anionic and cationic compounds and hydrophobic molecules from complex natural matrices (Başkan, Öztekin \& Erim 2007).

In the case of CE, a sample, which usually contains charged species, is introduced into the end of a capillary that has been filled with a buffer solution (or electrolyte). Under the influence of an electric field, the analytes migrate away from the injection end of the capillary toward the detector end, where they are visualized. Three distinct mechanisms have been developed for the separation of analytes by CE: 1 . The first mechanism is based on the mobility differences of the analytes in an electric field (these differences are dependent on the size and charge-to-mass ratio of the analyte ion), 2. The second separation mechanism is found in capillary isoelectric focusing where analytes are separated on the basis of isoelectric points and 3. The third mechanism is found in capillary isotachophoresis, where all the solutes travel at the same velocity through the capillary but are separated on the basis of differences in their mobility (Weston \& Brown, 1997). 
The advantages of CE are: a rapid and an economical methodology (Ballus et al. 2012), they do not require a pre-separation process, the consumption of reagents is low, they generate less toxic waste compared with other separation techniques and could be applicable to the quality control of plants (Başkan, Öztekin \& Erim 2007). The main advantages of CE compared with HPLC are its higher resolving power and its selectivity. It is useful for the detection of some very polar compounds that cannot be analyzed by RP-HPLC. Moreover, the possibilities of the CE approach for following the degradation of antioxidants has also been demonstrated (Crego et al. 2004).

The CE methods have been applied for the identification of anthocyanin. Calvo et al. (2004) separated and identified 13 anthocyanins in wine using an electrophoregram. Another CE mode that has been used in the analysis of anthocyanins is micellar electrochromatography [MEKC] (Bednar et al. 2003). By using this mode, a method for simultaneously separating 6 anthocyanins (Mv-3,5-diglc, Mv-3-glc, Mv-3-gal, Pg-3-glc, Cy-3,5-diglc and Cy-3-gal) was developed (Castañeda-Ovando et al.2009).

Supercritical fluid extraction / Capillary electrophoresis - Ultraviolet detection (SFE/CEUV) method is a reliable, efficient analytical tool which uses a simple background electrolyte and the normal polarity mode for the determination of rosmarinic and caffeic acids present in virgin olive oil enriched with natural antioxidants (Berzas Nevado, Rodríguez Robledo \& SánchezCarnerero 2012).

Galeano-Díaz, Acedo-Valenzuela \& Silva-Rodriguez (2012) developed a new CE method using the fluorescence detection of tocopherols in vegetable oils; the fluorescence detection improved the sensitivity and the selectivity. 
Capillary electrophoresis is excellent for the simultaneous separation of 16 phenolic compounds (e.g. rutin, myricetin, kaemppferol, quercetin, natitutin, morin, $(-)-$ epicatechin, $(+)-$ catechin, cinnamic acid, trans-resveratrol, ferulic acid, vanillic acid, gallic acid, caffeic acid and 3,4-dihydroxybenzoic acid) present in red, white and rosé wines (Ballus et al. 2012). This method is fast and consumes little reagent.

Lee, Boyce \& Breadmore (2011) have developed a fast CE method (7 min) for determining sinapic, $p$-coumaric, ferulic and caffeic acids from broccoli, broccolini, Brussel sprouts, cabbage and cauliflower.

\subsubsection{Nuclear magnetic resonance (NMR)}

Nuclear magnetic resonance (NMR) is a rapid, non-invasive and non-destructive technique. NMR offers the opportunity to recognize a given compound without an internal standard (Soininen et al. 2012) and without any preparative manipulation which could alter, among others, the real distribution of water in the sample (Ruan \& Chen, 2001). It is a powerful tool for simultaneously profiling diverse compounds in the food matrix (Rochfort et al. 2010). In ${ }^{1} \mathrm{HNMR}$, hydrogen atoms are selectively targeted, submitted to a strong magnetic field and excited by a radio frequency $(\mathrm{RF})$. After the RF pulses, the excited nuclei emit and the absorbed energy is monitored. The signals obtained are related to the chemical and physical environments surrounding the spins and, therefore, different information can be extracted from them (Otero \& Préstamo, 2009).

NMR spectroscopy has been widely recognized as the most important tool for the structural elucidation of flavonoids (Fossen \& Andersen, 2006) and it is also increasingly used as an analytical tool for the evaluation of quality traits in foods (Le Gall, Puaud \& Colquhoun 2001). Together with its undisputed potential in structural elucidation, NMR has other advantages such 
as quick sample preparation and short analysis time, and its total sample recovery permits distinguishing stereoisomers and makes it possible to identify the two epimeric forms of flavone glycosides (Maltese et al. 2009) or for tannin isomers (Chai et al. 2012).

NMR spectroscopy was applied for determining the catechins (epicatechin, epigallocatechin, epicatechin-3-galate) presented in green tea during fermentation (Lee et al. 2011) and in the leaves of Maytenusilicifolia (de Souza et al.2008).

The NMR technique has been used for the structural elucidation of anthocyanins, as in the case of Acanthopanax senticosus (Siberian Ginseng) (Lee, Lim \& Choung 2013), tamarillo (Solanum betaceum Cav.) and Andes berry (Rubus glaucus Benth.) fruits (Osorio et al. 2012) and wine (Cui et al. 2013). Anthocyanins with rhamnoside derivatives are found in some fruits like blackberries (Longo \&Vasapollo, 2005), and in pomegranate flowers (Zhang, Fu \& Zhang 2011).

Khoo et al. (2011) reported a prediction of total phenolic content, total anthocyanin content and total antioxidant capacity of sour cherries by applying multivariate data analysis to ${ }^{1} \mathrm{H}-\mathrm{NMR}$ data.

\subsubsection{Near infrared spectroscopy}

Near infrared reflectance spectroscopy (NIRS) has been widely used as a fast, nondestructive, accurate and non-polluting method for qualitative and quantitative analysis in food and pharmaceutical fields for the last 30 years (Cen \& He, 2007, Roggo et al. 2007). Now, the near infrared (NIR) spectroscopic technique is being employed as an alternative to wet chemistry procedures for quantitative analysis in quality evaluation of agricultural and food products (Cen \& He, 2007). The principle of the NIRS technique is based on obtaining the content or the construction of different components of samples through the analysis of the spectrum information within the wavelength range of $800-2500 \mathrm{~nm}$. NIRS is recommended for the determination of 
antioxidants such as: total carotenoids in carrot fruit (Schulz et al. 1998) and wheat seeds (Atienza et al. 2005) and especially for individual carotenoids such as lycopene and lutein in tomato products (Pedro \& Ferreira, 2005), zeaxanthin and lutein in maize seeds (Brenna \& Berardo, 2004) and lutein and $\beta$-carotene in Chinese kale (Chen et al. 2009).

Infrared spectroscopy has been used for the prediction of procyanidins in cocoa, for the determination of total polyphenol content in green tea using FT-NIR (Chen et al. 2008), to evaluate phenolic changes occurring during the development of olive fruit using ATR (Attenuated total reflectance) - FT-IR (López-Sánchez, Ayora-Cañada \& Molina-Díaz 2009) and to determine

malvidin-3- glucoside, tannins and pigmented polymers in wine (Cozzolino et al. 2008) and grape skins (Ferrer-Gallego, 2011).

\subsubsection{Mass spectrometry (MS)}

Mass spectrometers are instruments that separate ionized atoms or molecules according to their difference in mass to charge ratio $(\mathrm{m} / \mathrm{z})$. Mass spectrometry is therefore useful for the quantification of atoms or molecules and, since molecules have distinctive fragmentation patterns, to provide structural information for the identification of structural components.

The main components of a mass spectrometer are: ion source, a mass-selective analyzer and the detector. Separation devices are used to increase the sensitivity, dynamic range and selectivity of the MS (e.g. gas chromatographic separation which can be made up before the mass spectrometric analysis, in online or offline mode).

The ionization methods

Prior to analysis in a mass spectrometer, molecules need to be ionized. Various ionization methods exist but the most standardized and one of the most common forms of ionization is 
electron ionization (EI), also called electron impact. Another method is chemical ionization (CI). The main ionization methods are presented in Table 5 .

Mass Analyzers

Mass analyzers are another one of the basic components of a mass spectrometer. After ionization occurs, the charged molecules enter another region of the mass spectrometer in which separation of the ion mixture occurs. Nowadays, there are many mass analyzer designs and variations that accomplish this task. Some analyzers not only separate charged ions from each other but also store and filter the ions. In other words, one analyzer can function in several modes. This multifunctioning ability often makes it advantageous to design mass spectrometers that utilize more than one type of analyzer in a single instrument. Mass analyzers measure the $\mathrm{m} / \mathrm{z}$ ratio. This becomes especially important when compounds take on several charges $(z)$ because the $m / z$ will be much less than the actual mass $(m)$ of the compound ( $\operatorname{Gad} 2012)$. The main types of mass analyzer, advantages, disadvantages and their application are described in Table 6.

Tab.1. Natural sources of antioxidants and their health benefits

Tab.2. Organic solvents used for antioxidant extraction Tab.3. Extraction procedure advantages and disadvantages

Tab. 4. HPLC procedures in the separation of different classes of antioxidant compounds Tab.5. Ionization methods: principle advantages and disadvantages

\begin{tabular}{|c|c|c|}
\hline Antioxidant & Natural sources & Health benefits \\
\hline \begin{tabular}{|l|} 
Vitamin $\mathbf{C}$ \\
\end{tabular} & $\begin{array}{ll}\text { - } & \text { apple (Bosch et al. 2013) } \\
\text { - } & \text { banana (Bosch et al. 2013) } \\
\text { - } & \text { bayberry (Yu et al. 2013) } \\
\text { broccoli (Rybarczyk- } \\
\text { Plonska et al. 2014) } \\
\text { - } \quad \text { citrus peel (Barros, Ferreira } \\
\quad \& \text { Genovese 2012) }\end{array}$ & $\begin{array}{l}\text { Vitamin } \mathrm{C} \text { is of great interest } \\
\text { due to the possibility of } \\
\text { increasing the resistance of } \\
\text { plasma to lipid peroxidation } \\
\text { in the case of short and long } \\
\text { term supplementation } \\
\text { (Polidori et al. 2004), in } \\
\text { lowering serum uric acid } \\
\text { levels, resulting in a }\end{array}$ \\
\hline
\end{tabular}




\begin{tabular}{|c|c|c|c|}
\hline & & $\begin{array}{ll}\text { - } & \text { garlic (Di Cagno et al. } \\
\text { 2013). } \\
\text { - } \\
\text { orange juice (Xu et al. } \\
\text { 2008) } \\
\text { - } \\
\text { - } \quad \text { straw (Bosch et al. 2013) } \\
\text { 2014) } \\
\text { - } \text { tangerine (Bosch et al. } \\
\text { 2013) } \\
\text { - peppermint (Curutchet et al. } \\
\text { 2014) } \\
\text { spearmint (Curutchet et al. } \\
\text { 2014) }\end{array}$ & $\begin{array}{l}\text { correspondingly lower } \\
\text { incidence of gout (Choi et al. } \\
\text { 2009), significantly decreases } \\
\text { the risk of having a stroke } \\
\text { (Myint et al. 2008), and } \\
\text { reduces the incidence of } \\
\text { chronic and degenerative } \\
\text { diseases (Wojcik, Burzynska- } \\
\text { Pedziwiatr \& Wozniak 2010, } \\
\text { Liu et al. 2008, Serafini \& } \\
\text { Testa, 2009) }\end{array}$ \\
\hline \multicolumn{2}{|c|}{ Vitamin E } & $\begin{array}{ll}\text { - } & \text { dabai (Azlan et al. 2010) } \\
\text { - } & \text { grains (Gerstenmeyer et al. } \\
\text { 2013, Miller et al. 2000, } \\
\text { Okarter et al. 2010) } \\
\text { - } \quad \text { green tea (Yin et al, 2012) } \\
\text { - olives and olive oil (Beltrán } \\
\text { et al. 2010, Azlan et al. } \\
\text { 2010) } \\
\text { - } \quad \text { palm oil (Azlan et al. 2010) } \\
\text { - } \text { pumpkin seeds (Butinar et } \\
\text { al. 2011) } \\
\text { - } \quad \text { sunflower seeds and } \\
\text { sunflower oil (Aladedunye } \\
\text { \& Przybylski 2013) } \\
\end{array}$ & $\begin{array}{l}\text { Vitamin } \mathrm{E} \text { is believed to be the } \\
\text { primary components of the } \\
\text { antioxidant system of the } \\
\text { spermatozoa (Surai et al. } \\
\text { 1998), and is one of the major } \\
\text { membrane protectants against } \\
\text { reactive oxygen species and } \\
\text { lipid peroxidation (Yousef } \\
\text { 2010). }\end{array}$ \\
\hline \multicolumn{2}{|c|}{ Carotenoids } & $\begin{array}{l}\text { grains (Gerstenmeyer et al. } \\
\text { 2013, Miller et al. 2000) } \\
\text { - } \quad \text { orange juice (Xu et al. } \\
\text { 2008) } \\
\text { - Parsley, celery, basil, } \\
\text { coriander, dill (Pokorny \& } \\
\text { Panek 2012) } \\
\text { - peppermint (Curutchet et al. } \\
\text { 2014) } \\
\text { spearmint (Curutchet et al. } \\
\text { 2014) }\end{array}$ & $\begin{array}{l}\text { Carotenoids have been shown } \\
\text { to play a range of roles in the } \\
\text { prevention against various } \\
\text { health disorders, including } \\
\text { cancer, metabolic disease and } \\
\text { possibly cardiovascular } \\
\text { disease (Jomova \& Valko } \\
\text { 2013) }\end{array}$ \\
\hline Carotenes & $\begin{array}{l}\beta- \\
\text { carotene }\end{array}$ & 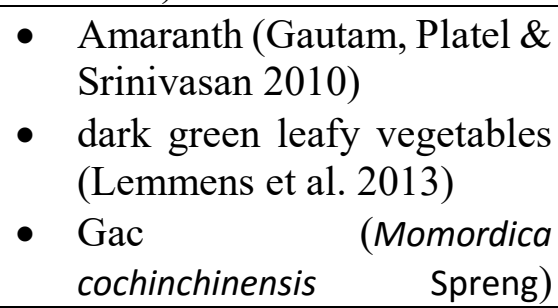 & $\begin{array}{l}\text { It has been reported that } \beta \text { - } \\
\text { carotene is associated with } \\
\text { positive influence on certain } \\
\text { types of cancer (Greenlee } \\
\text { 2012) and cardiovascular } \\
\text { diseases (Key 2011). }\end{array}$ \\
\hline
\end{tabular}




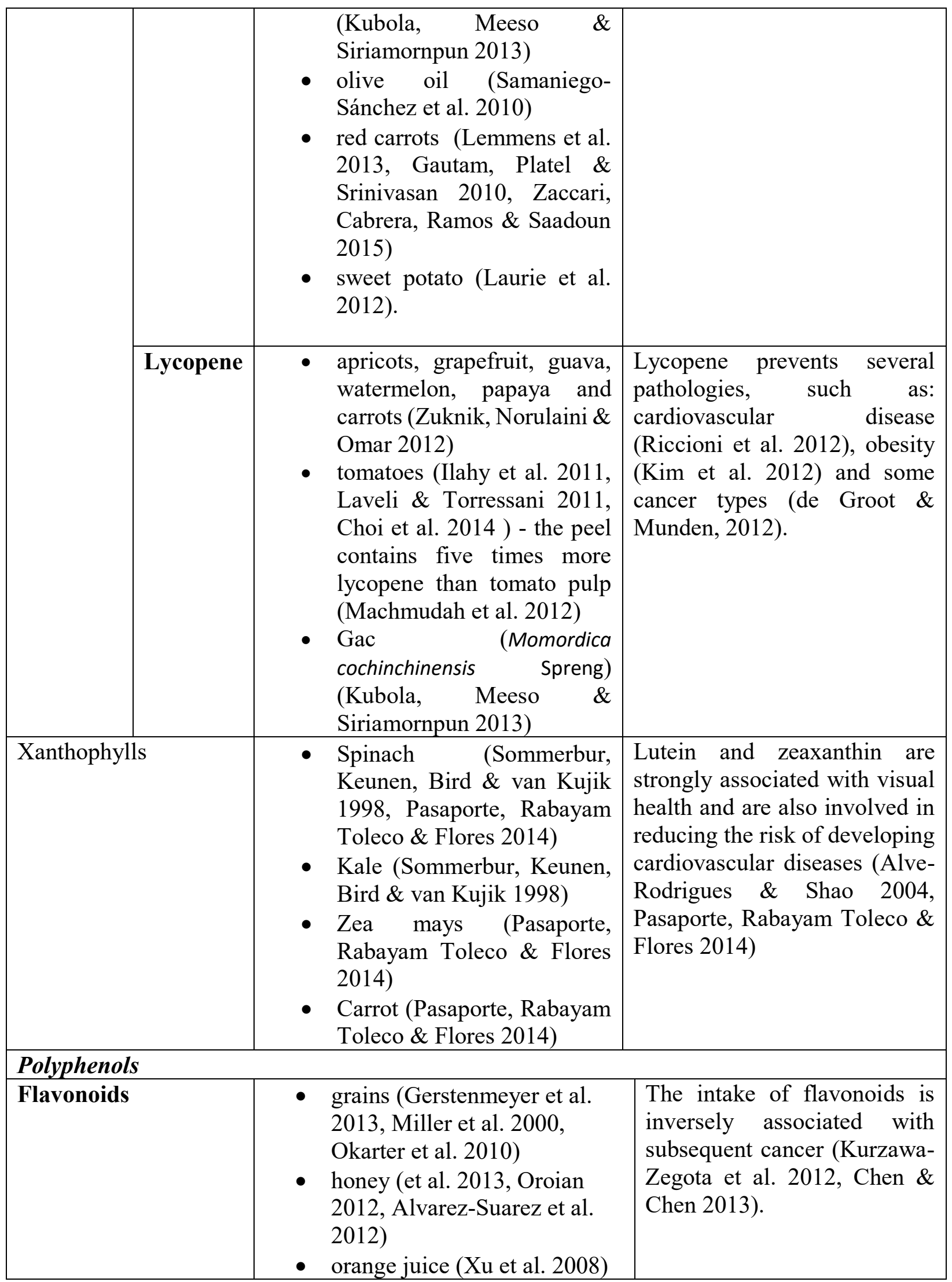




\begin{tabular}{|c|c|c|}
\hline & $\begin{array}{ll} & \text { Tsaoko amomum fruit (Lu, } \\
\text { Yuan, Zeng \& Chen 2011) } \\
\text { Drumstick (Moringa oleifera) } \\
\text { (Moyo, Oyedemi, Masika \& } \\
\text { Muchenje 2012) }\end{array}$ & \\
\hline Flavonols & 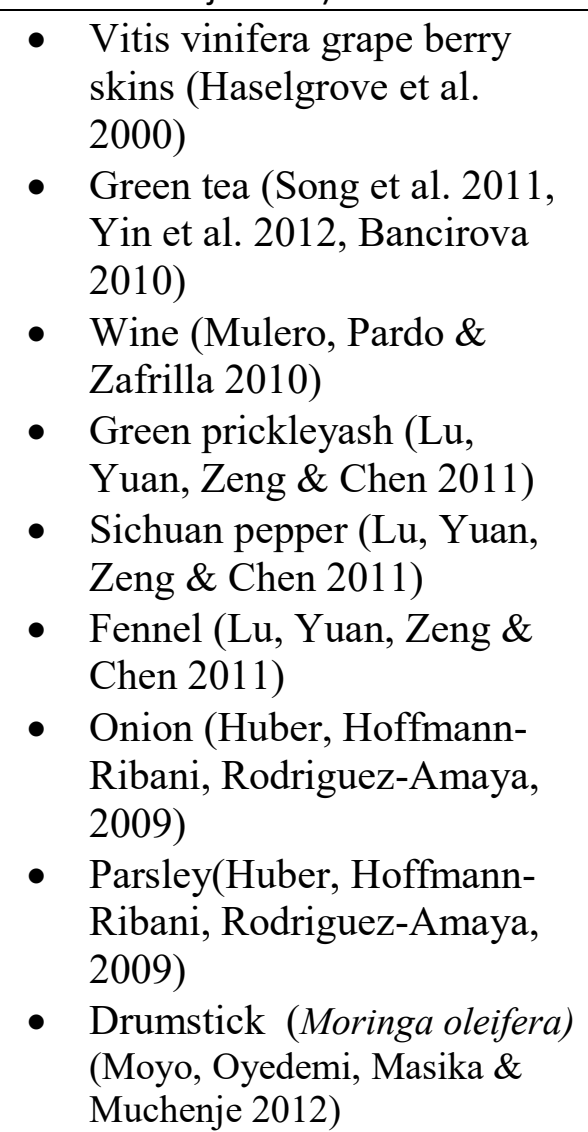 & $\begin{array}{l}\text { Studies have shown that } \\
\text { quercetin, which is the major } \\
\text { flavonol present in onions, } \\
\text { exhibits anti-cancer, anti- } \\
\text { inflammatory, anti-viral } \\
\text { activity, and may also prevent } \\
\text { cardiovascular disease in } \\
\text { humans (Caridi et al. 2007). }\end{array}$ \\
\hline Flavones & $\begin{array}{ll}\text { - } & \text { Citrus peel (Barros, Ferreira } \\
& \text { \& Genovese 2012) } \\
\text { - } & \text { Trollflowers (Sun et al. 2013) } \\
\text { - Onion (Huber, Hoffmann- } \\
\text { Ribani, Rodriguez-Amaya, } \\
\text { 2009) } \\
\text { - Parsley(Huber, Hoffmann- } \\
\text { Ribani, Rodriguez-Amaya, } \\
\text { 2009) } \\
\text { - Corn silk (Zea mays L.) (Liu } \\
\text { et al. 2011) }\end{array}$ & $\begin{array}{l}\text { The flavones have antioxidant } \\
\text { (Gulcin 2009), anti-cancer } \\
\text { (Yuan et al. 2011), anti- } \\
\text { inflammation (Hou \& } \\
\text { Kumamoto, 2010), } \\
\text { neuroprotective (Yu, He \& } \\
\text { Du, 2012), anti-diabetes } \\
\text { (Chiarelli \& Marzio, 2008), } \\
\text { anti-ulcer (Sumbul, Ahmad \& } \\
\text { Mohd 2011) and anti- } \\
\text { microbial effects (Sagrera, } \\
\text { Bertucci, Vazqueq, Seoane } \\
\text { 2011) }\end{array}$ \\
\hline Flavanones & $\begin{array}{l}\text { Lemons, limes, sweet } \\
\text { oranges, tangerine and tangor } \\
\text { species of citrus fruits (Khan, } \\
\text { Huma \& Dangles 2014) }\end{array}$ & $\begin{array}{l}\text { As a flavanone, naringenin } \\
\text { exhibits antioxidant and } \\
\text { antidiabetic activity (Ortiz- } \\
\text { Andrade et al. 2008) as well as } \\
\text { demonstrating }\end{array}$ \\
\hline
\end{tabular}




\begin{tabular}{|c|c|c|}
\hline & $\begin{array}{l}\text { Black sorghums (Dykes, } \\
\text { Rooney \& Rooney, 2013) } \\
\text { Deffated olive (Alu'datt, } \\
\text { Rababah, Ereifej \& Alli } \\
\text { 2013) } \\
\text { - Deffated soybean (Alu'datt, } \\
\text { Rababah, Ereifej \& Alli } \\
\text { 2013) }\end{array}$ & $\begin{array}{l}\text { antiproliferative properties in } \\
\text { cervical cancer (Ramesh \& } \\
\text { Alshatwi 2013). Naringenin } \\
\text { inhibits gastrointestinal } \\
\text { smooth muscle contractility in } \\
\text { isolated animal tissues } \\
\text { (Amira, Rotondo \& Mulè } \\
\text { 2008), and chloride secretion } \\
\text { in isolated colonic epithelia } \\
\text { (Collins et al. 2011). This } \\
\text { compound has a wide } \\
\text { spectrum pharmacological } \\
\text { properties such as anti- } \\
\text { inflammatory, } \\
\text { anticarcinogenic, } \\
\text { antihypertensive and anti- } \\
\text { atherogenic (Rodrigo et al. } \\
\text { 2012) and also exhibits } \\
\text { antioxidant properties } \\
\text { (Shagirtha \& Pari, 2011). }\end{array}$ \\
\hline Anthocyanins & 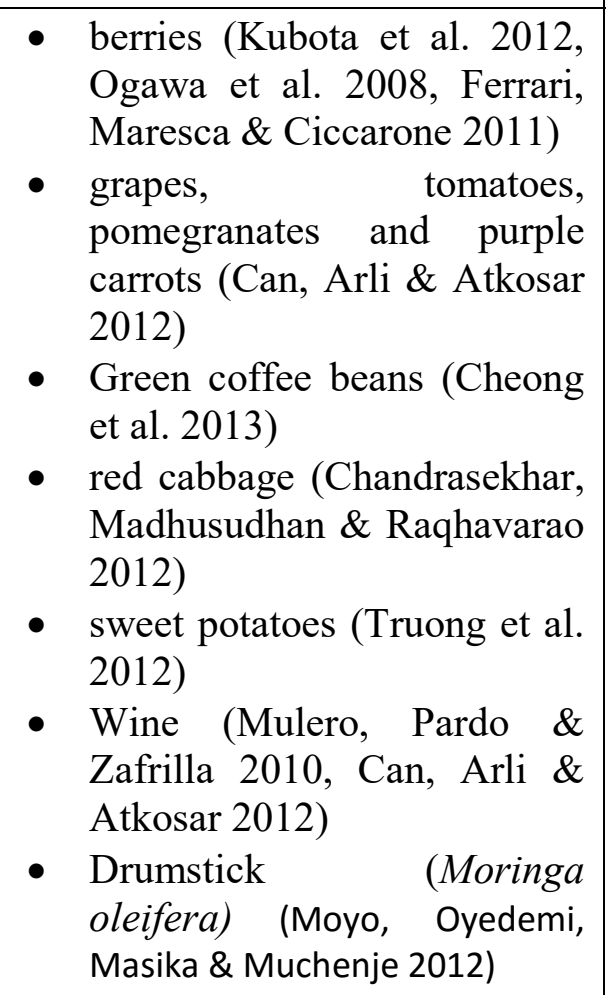 & $\begin{array}{l}\text { Anthocyanins exert beneficial } \\
\text { effects on humans; they } \\
\text { exhibit antioxidant, and } \\
\text { anticarcinogenic activity (Hui } \\
\text { et al. 2010). It is proved that } \\
\text { the administration of } \\
\text { anthocyanins for } 4 \text { weeks } \\
\text { decreases myopia (Lee at al. } \\
\text { 2005), apoptosis, diabetes and } \\
\text { obesity symptoms (Tsuda } \\
\text { 2012). }\end{array}$ \\
\hline Isoflavones & $\begin{array}{l}\text { - soybean (Messina \& Wood, } \\
\text { 2008, Rimbach et al. 2008, } \\
\text { Toro-Funes et al. 2012, }\end{array}$ & $\begin{array}{l}\text { Isoflavones have a large } \\
\text { spectrum of functional } \\
\text { benefits on the human body, } \\
\text { such as reduction of }\end{array}$ \\
\hline
\end{tabular}




\begin{tabular}{|c|c|c|}
\hline & $\begin{array}{l}\text { Balisteiro, Rombaldi \& } \\
\text { Genovese 2013) } \\
\text { green, yellow and red lentils, } \\
\text { red kidney beans, haricot } \\
\text { beans and chickpeas (Konar } \\
\text { et al. 2012). }\end{array}$ & $\begin{array}{l}\text { cardiovascular risk (Rimbach } \\
\text { et al. 2008), postmenopausal } \\
\text { symptoms (Espin et al. 2007) } \\
\text { or cancer (Messina \& Wood, } \\
2008 \text { ). }\end{array}$ \\
\hline Phenolic acids & 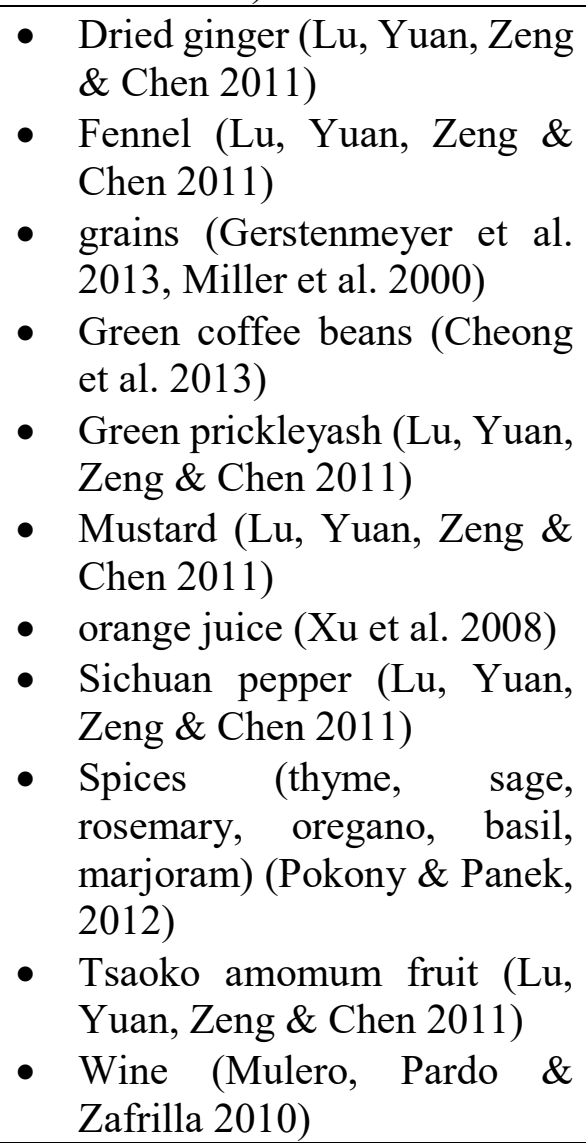 & $\begin{array}{l}\text { The phenolic acids are } \\
\text { powerful antioxidants and } \\
\text { have been reported to } \\
\text { demonstrate antibacterial, } \\
\text { antiviral, anticarcinogenic, } \\
\text { anti-inflammatory and } \\
\text { vasodilatory actions (Duthie } \\
\text { et al. 2000, Mattila \& } \\
\text { Hellstrom 2007). }\end{array}$ \\
\hline Tannins & $\begin{array}{l}\text { - Chinese olives (He, Xia \& } \\
\text { Chen 2007) } \\
\text { - Condensed tannins are } \\
\text { present in bean seed coats } \\
\text { (Díaz, Caldas \& Blair 2010), } \\
\text { persimmons (Tian et al. } \\
\text { 2012), mangosteens (Zhou et } \\
\text { al. 2011) and canola (Khattab } \\
\text { et al. 2010). } \\
\text { - Green coffee beans (Cheong } \\
\text { et al. 2013) } \\
\text { Hydrolysable gallotannins } \\
\text { can be present in wine from } \\
\text { oak, and could be added as } \\
\text { oenotannins during } \\
\text { winemaking (traditionally to }\end{array}$ & $\begin{array}{l}\text { Tannins have been reported to } \\
\text { have anti-thrombotic, anti- } \\
\text { atherogenic (Erlund et al. } \\
\text { 2008), anti-mutagenic, anti- } \\
\text { diabetic and anti-proliferative } \\
\text { effects (Landete 2011, } \\
\text { Larrosa et al. 2010), anti- } \\
\text { carcinogenic (Nichenametla } \\
\text { et al. 2006), anti- } \\
\text { inflammatory (Terra et al. } \\
\text { 2007), antiviral (Kwon et al. } \\
\text { 2010) and antibacterial } \\
\text { properties (Tossi et al. 2007). } \\
\text { They induce vascular } \\
\text { relaxation (Roussis, } \\
\text { Lambropoulos \& Soulti 2005, } \\
\text { del Alamo et al. 2004) and }\end{array}$ \\
\hline
\end{tabular}




\begin{tabular}{|c|c|c|}
\hline & $\begin{array}{l}\text { remove undesirable proteins) } \\
\text { (Harbertson et al. 2012). } \\
\text { - mango kernels (Engels, } \\
\text { Ganzle \& Schieber 2010) } \\
\text { - } \text { pomegranates (Madrigal- } \\
\text { Carballo et al. 2009) } \\
\text { - strawberries (Aaby et al } \\
\text { 2007) } \\
\text { - walnuts (Fukuda, Ito \& } \\
\text { Yoshida 2008) } \\
\text { - whisky (Fujieda et al. 2008) }\end{array}$ & $\begin{array}{l}\text { inhibits oxidation of oil } \\
\text { systems (Kovacevic Ganicet } \\
\text { al. 2006). }\end{array}$ \\
\hline Stilbenes & $\begin{array}{l}\text { - Almonds (Xie \& Bolling, } \\
\text { 2014) } \\
\text { - Chocolate and cocoa (Counet, } \\
\text { Callemien \& Collin 2006). } \\
\text { - Peanuts and peanut butter } \\
\text { (Liu et al. 2013) } \\
\text { - Seeds and skins of grapes, red } \\
\text { wine (Mulero, Pardo \& } \\
\text { Zafrilla 2010, Liu et al. 2013) }\end{array}$ & $\begin{array}{l}\text { The stilbenes have: } \\
\text { antioxidant and antimicrobial } \\
\text { efficiency, prevent } \\
\text { cardiovascular disease, } \\
\text { arteriosclerosis and cancer } \\
\text { acting and act as anti- } \\
\text { inflammatory and antiviral } \\
\text { agents (Chong, Poutaraud \& } \\
\text { Hugueney 2009). }\end{array}$ \\
\hline Lignans & 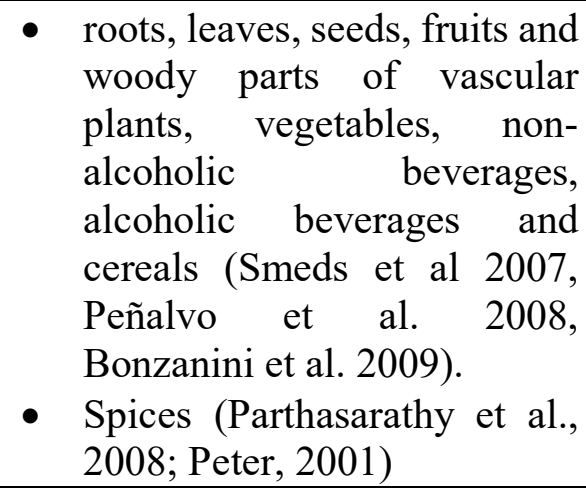 & $\begin{array}{l}\text { Lignans are antioxidants and } \\
\text { they play a role in normal } \\
\text { colon functioning, and } \\
\text { inhibit/delay the growth of } \\
\text { experimental mammary } \\
\text { cancer (Landete 2012). }\end{array}$ \\
\hline
\end{tabular}

\begin{tabular}{|l|l|l|}
\hline Techniques & Advantages & Disadvantages \\
\hline $\begin{array}{l}\text { Extraction with } \\
\text { solvents }\end{array}$ & $\begin{array}{l}\text { Inexpensive } \\
\text { Can be performed with } \\
\text { simple equipment and can be } \\
\text { automated. } \\
\text { The solvent can be reused }\end{array}$ & $\begin{array}{l}\text { Low selectivity, low extraction } \\
\text { efficiency, solvent residue, multiple } \\
\text { extractions might be required and } \\
\text { environmental pollution (Herrero, } \\
\text { Cifuentes \& Ibanez, 2006, Wang et } \\
\text { al. 2010) } \\
\end{array}$ \\
& $\begin{array}{l}\text { Time consuming, high temperature } \\
\text { (Wang, Dong \& Tong, 2013) } \\
\text { Multiple extractions might be }\end{array}$ \\
\hline
\end{tabular}




\begin{tabular}{|c|c|c|}
\hline $\begin{array}{l}\text { Extraction with } \\
\text { supercritical fluids }\end{array}$ & $\begin{array}{l}\text { Non-toxic, environmentally } \\
\text { friendly, non-flammable } \\
\text { (Rial-Otero et al. 2007) } \\
\text { The fluids are easily removed } \\
\text { from the product } \\
\text { It has a convenient critical } \\
\text { temperature ( } 31.04^{\circ} \text { C). This } \\
\text { enables extractions to be } \\
\text { carried out at comparatively } \\
\text { low temperature (often as low } \\
\text { as } 40 \text { or } 50^{\circ} \text { C), decreasing the } \\
\text { risk of damage of } \\
\text { thermalabile compounds } \\
\text { The number of solvents } \\
\text { possible to be used on } \\
\text { supercritical extraction is } \\
\text { superior to classic organic } \\
\text { solvents } \\
\text { Supercritical fluids have a } \\
\text { superior selectivity although } \\
\text { they have an inferior solvent } \\
\text { power than classic organic } \\
\text { solvents } \\
\text { Supercritical extraction can } \\
\text { be connected directly to a } \\
\text { chromatograph, allowing } \\
\text { analysis immediately after } \\
\text { extraction } \\
\text { (Abbas, Mohamed, } \\
\text { Abdulamir \& Abbas } 2008 \text { ) }\end{array}$ & $\begin{array}{l}\text { An important drawback of } \\
\text { supercritical extraction and most of } \\
\text { the other supercritical fluids is that } \\
\text { predominantly, a non-polar } \\
\text { extraction fluid, such as } \mathrm{CO}_{2} \text {, is } \\
\text { used. (Abbas, Mohamed, Abdulamir } \\
\& \text { Abbas 2008) }\end{array}$ \\
\hline $\begin{array}{l}\text { Microwave-assisted } \\
\text { extraction }\end{array}$ & $\begin{array}{l}\text { Less solvent and energy, not } \\
\text { time consuming (Chemat, } \\
\text { Abert-Vian \& Visinoni 2008) } \\
\text { High efficiency (Ballards et } \\
\text { al. 2010) } \\
\text { reduced extraction time, } \\
\text { reduced solvent consumption, } \\
\text { and less environmental } \\
\text { pollution as a result of } \\
\text { increased efficiency and clean } \\
\text { transfer of energy to the }\end{array}$ & $\begin{array}{l}\text { Additional filtration or centrifugation } \\
\text { is necessary to remove the solid } \\
\text { residue after the process; } \\
\text { the efficiency of microwaves can be } \\
\text { poor when the target compounds or } \\
\text { solvents are nonpolar, or when they } \\
\text { are volatile; and the use of high } \\
\text { temperatures that can lead } \\
\text { to degradation of heat-sensitive } \\
\text { bioactive compounds (Veggi, } \\
\text { Martinez \& Meireles 2013) }\end{array}$ \\
\hline
\end{tabular}




\begin{tabular}{|c|c|c|}
\hline & $\begin{array}{l}\text { matrix; improved extraction } \\
\text { yield and product quality, } \\
\text { because materials can be } \\
\text { rapidly heated, and often } \\
\text { processed at lower } \\
\text { temperatures; up to } 70 \% \\
\text { energy saving compared to } \\
\text { conventional energy forms } \\
\text { from the high energy } \\
\text { densities and the direct } \\
\text { absorption of energy by the } \\
\text { materials; compact systems, } \\
\text { as small as 20\% of the size of } \\
\text { conventional systems; and } \\
\text { selective energy absorption } \\
\text { resulting from the dielectric } \\
\text { properties of the material and } \\
\text { applicator design (Clayton } \\
\text { 1999, Michel, Destandau \& } \\
\text { Elfakir 2011, Yuan et al. } \\
\text { 2012, Veggi, Martinez \& } \\
\text { Meireles 2013) }\end{array}$ & \\
\hline $\begin{array}{l}\text { Subcritical water } \\
\text { extraction (SWE) }\end{array}$ & $\begin{array}{l}\text { Less expensive operation, } \\
\text { environmentally friendly, } \\
\text { lower working temperatures } \\
\text { (thus avoiding losses and } \\
\text { degradation of volatile and } \\
\text { thermostabile compounds), it } \\
\text { is a selective method, because } \\
\text { by means of kinetic } \\
\text { experiments, it is possible to } \\
\text { manipulate the extract } \\
\text { composition under given } \\
\text { working conditions and higher } \\
\text { quality of the extracts (He et } \\
\text { al. 2012). }\end{array}$ & $\begin{array}{l}\text { More laborious and time-consuming } \\
\text { method (He et al. 2012). }\end{array}$ \\
\hline Ultrasonics (US) & $\begin{array}{l}\text { Ultrasonic extraction is a } \\
\text { simple, efficient and } \\
\text { inexpensive alternative to } \\
\text { conventional extraction } \\
\text { techniques (Huang et al. } \\
\text { 2009). Moreover, there is no } \\
\text { chemical involvement in the }\end{array}$ & $\begin{array}{l}\text { Need to be applied for a long time (1 } \\
\text { h) at a high temperature }\left(70^{\circ} \mathrm{C}\right) \text { to } \\
\text { significantly increase the yield of } \\
\text { polyphenols (Corrales et al. } 2008)\end{array}$ \\
\hline
\end{tabular}




\begin{tabular}{|c|c|c|}
\hline & $\begin{array}{l}\text { ultrasonic extraction, which } \\
\text { can prevent possible chemical } \\
\text { degradation of target } \\
\text { compounds (Wang \& Weller, } \\
2006 \text { ). } \\
\text { Ultrasonic-assisted extraction } \\
\text { can be carried out at lower } \\
\text { temperatures, avoiding } \\
\text { thermal damage to the } \\
\text { extracts and the loss of } \\
\text { volatile components on } \\
\text { boiling (Wu, Lin \& Chau } \\
\text { 2001). } \\
\text { Environmentally friendly } \\
\text { (Wu, Zhu, Diao \& Wang } \\
\text { 2014) }\end{array}$ & \\
\hline $\begin{array}{l}\text { Pulsed electric fields } \\
\text { (PEF) }\end{array}$ & $\begin{array}{l}\text { Replace the enzymatic } \\
\text { maceration of the plant tissue, } \\
\text { works on an entire mash flow, } \\
\text { keeps the product temperature } \\
\text { almost unchanged cost- } \\
\text { effective because uses the } \\
\text { latest advances in pulsed } \\
\text { power technology (Corrales et } \\
\text { al. 2008) }\end{array}$ & $\begin{array}{l}\text { It's effectiveness is } 50 \% \text { of the } \\
\text { HVED (in the case of polyphenols } \\
\text { yields) (Bousetta et al. 2009) }\end{array}$ \\
\hline $\begin{array}{l}\text { High hydrostatic } \\
\text { pressure (HHP) }\end{array}$ & $\begin{array}{l}\text { It can obtain a single } \\
\text { component of high purity. } \\
\text { Strong, weak and non-polar } \\
\text { compounds can all be } \\
\text { extracted. } \\
\text { Energy saving method } \\
\text { (Kumar, Chu, Krishaiah \& } \\
\text { Bono, 2006) }\end{array}$ & $\begin{array}{l}\text { Complex material handling, little } \\
\text { flexiblility in choice of container, } \\
\text { greater dead time in use of pressure } \\
\text { (Mathavi, Sujatha, Ramaya \& Devi } \\
\text { 2013) }\end{array}$ \\
\hline $\begin{array}{l}\text { High voltage } \\
\text { electrical discharges } \\
\text { (HVED) }\end{array}$ & $\begin{array}{l}\text { short times of treatment (a } \\
\text { few ms) and low energy } \\
\text { consumption }(10-50 \mathrm{~kJ} / \mathrm{kg}) \\
\text { (Gros, Lanoiselle \& } \\
\text { Vorobiev, 2003) }\end{array}$ & $\begin{array}{l}\text { Slow rate of material removal, } \\
\text { The addition time and cost for } \\
\text { creating electrodes } \\
\text { Reducing sharp corners on the } \\
\text { workpiece is difficult due to } \\
\text { electrode wear (Rajha et al. 2014) }\end{array}$ \\
\hline
\end{tabular}




\begin{tabular}{|l|l|l|}
\hline & $\begin{array}{l}\text { High extraction yields of } \\
\text { polyphenols compared with } \\
\text { PEF and US (Rajha et al. } \\
\text { 2014) }\end{array}$ & \\
\hline $\begin{array}{l}\text { enzyme-assisted } \\
\text { extraction }\end{array}$ & $\begin{array}{l}\text { High extraction yield, } \\
\text { enhances the release of } \\
\text { secondary plant metabolites } \\
\text { and preserves the bioactive } \\
\text { properties of the extracts (Li, } \\
\text { Smith \& Hossain 2006). } \\
\text { Energy - saving (Wang, } \\
\text { Dong \& Tong, 2013) } \\
\text { Environmentally friendly } \\
\text { (Wu, Zhu, Diao \& Wang }\end{array}$ & $\begin{array}{l}\text { Long time required and the high cost } \\
\text { of enzymes that makes this strategy }\end{array}$ \\
& $\begin{array}{l}\text { and (Martinez-Maqueda et } \\
\text { 2014) }\end{array}$ \\
\hline
\end{tabular}

\begin{tabular}{|c|c|c|c|}
\hline $\begin{array}{l}\text { Ionization } \\
\text { method }\end{array}$ & Principle & Advantage & Disadvantages \\
\hline $\begin{array}{l}\text { Electrospray } \\
\text { ionization (EI) }\end{array}$ & $\begin{array}{l}\text { EI can be applied to virtually all } \\
\text { volatile compounds and the } \\
\text { fragmentation provides } \\
\text { structural information. } \\
\text { Electrospray ionization takes } \\
\text { place directly from solution. EI } \\
\text { is the tool most widely used in } \\
\text { LC-MS and is applied in the } \\
\text { analysis of polar compounds } \\
\text { and heat-labile compounds or } \\
\text { compounds with higher } \\
\text { molecular weight (compared to } \\
\text { APCI). In EI, the sample } \\
\text { solution is passed at } \\
\text { atmospheric pressure through a } \\
\text { capillary where high voltage is } \\
\text { applied (typically } 3-4 \mathrm{kV} \text { ) }\end{array}$ & $\begin{array}{l}\text { Low sample consumption } \\
\text { and rapid analysis time. Ions } \\
\text { produced by electrospray } \\
\text { can be multiply charged, a } \\
\text { fact which enables } \\
\text { macromolecular analysis. } \\
\text { Furthermore, commercial } \\
\text { libraries with hundreds of } \\
\text { thousands of mass spectra } \\
\text { are available and can be } \\
\text { easily interrogated for EI } \\
\text { mass spectral "fingerprint". } \\
\text { Electrospray ionization } \\
\text { method has the major } \\
\text { advantage of desolvation at } \\
\text { relatively low temperatures } \\
\text { (typically room temperature } \\
\text { to } 80^{\circ} \mathrm{C} \text { ) so as not to } \\
\text { generate fragments }\end{array}$ & $\begin{array}{l}\text { A major disadvantage is that } \\
\text { this technique cannot analyze } \\
\text { mixtures very well, and when } \\
\text { forced to do so, the results are } \\
\text { unreliable. The apparatus is } \\
\text { also very difficult to clean and } \\
\text { has a tendency to become } \\
\text { overly contaminated with } \\
\text { residues from previous } \\
\text { experiments. Finally, the } \\
\text { multiple charges that are } \\
\text { attached to the molecular ions } \\
\text { can make for confusing spectral } \\
\text { data. This confusion is further } \\
\text { fueled by use of a mixed } \\
\text { sample, which is yet another } \\
\text { reason why mixtures } \\
\text { should be avoided when using } \\
\text { an electrospray ionization mass } \\
\text { spectrometer. }\end{array}$ \\
\hline $\begin{array}{l}\text { Chemical } \\
\text { ionization }(\mathrm{CI})\end{array}$ & $\begin{array}{l}\text { Chemical ionization uses ion- } \\
\text { molecule reactions to produce } \\
\text { ions from the analyte. EI and CI } \\
\text { share the same basic setup and } \\
\text { source design (in fact, it is quite } \\
\text { common for many ion sources }\end{array}$ & $\begin{array}{l}\text { Chemical ionization is a } \\
\text { lower-energy alternative to } \\
\text { EI for the analysis of } \\
\text { volatile molecules. CI } \\
\text { provides simple mass } \\
\text { spectra with reduced }\end{array}$ & $\begin{array}{l}\text { Molecule must have Lewis or- } \\
\text { acid functional group. } \\
\text { More external upkeep and cost } \\
\text { (gas cylinders). } \\
\text { Poor fragmentation produces } \\
\text { fragment patterns that are not }\end{array}$ \\
\hline
\end{tabular}




\begin{tabular}{|c|c|c|c|}
\hline & $\begin{array}{l}\text { to work in dual EI and CI } \\
\text { ionization mode). The chemical } \\
\text { ionization process begins when } \\
\text { a reagent gas such as methane, } \\
\text { isobutane, or ammonia (the } \\
\text { most common gases routinely } \\
\text { employed) is ionized by } \\
\text { electron impact. A high reagent } \\
\text { gas pressure (or long reaction } \\
\text { time) results in ion-molecule } \\
\text { reactions between the reagent } \\
\text { gas ions and reagent gas } \\
\text { neutrals. }\end{array}$ & $\begin{array}{l}\text { fragmentation compared to } \\
\text { EI. One advantage is that CI } \\
\text { often gives molecular } \\
\text { weight information through } \\
\text { molecular-like ions such as } \\
{[\mathrm{M}+\mathrm{H}]^{+} \text {. }}\end{array}$ & $\begin{array}{l}\text { informative or reproducible } \\
\text { enough for library search. }\end{array}$ \\
\hline $\begin{array}{l}\text { Atmospheric } \\
\text { pressure } \\
\text { chemical } \\
\text { ionization } \\
\text { (APCI) }\end{array}$ & $\begin{array}{l}\text { APCI uses gas-phase ion } \\
\text { molecule reactions at } \\
\text { atmospheric pressure in } \\
\text { analogy to GC using CI. APCI } \\
\text { is a soft ionization technique } \\
\text { used to analyze nonpolar to } \\
\text { medium polarity compounds } \\
\text { and compounds of low } \\
\text { molecular weight. }\end{array}$ & $\begin{array}{l}\text { Good for less-polar } \\
\text { compounds, } \\
\text { LC/MS interface. } \\
\text { Compatible with MS/MS } \\
\text { methods } \\
\text { Low to slightly high polar } \\
\text { compounds can be analyzed } \\
\text { Higher LC flow rates ( } 2 \\
\text { ml/min) can be used } \\
\text { Higher tolerance to buffers } \\
\text { in the mobile phase. }\end{array}$ & $\begin{array}{l}\text { Low reproducibility } \\
\text { The analyte analyzed must be } \\
\text { volatile } \\
\text { APCI does not function well at } \\
\text { lower LC flow rates, and may } \\
\text { contain more analyte-buffer } \\
\text { adducts in mass spectra. }\end{array}$ \\
\hline $\begin{array}{l}\text { Matrix- } \\
\text { assisted laser } \\
\text { desorption } \\
\text { (MALDI) }\end{array}$ & $\begin{array}{l}\text { MALDI is based on the } \\
\text { bombardment of sample } \\
\text { molecules with a laser light to } \\
\text { bring about sample ionisation. } \\
\text { The sample is pre-mixed with a } \\
\text { highly absorbing matrix } \\
\text { compound for the most } \\
\text { consistent and reliable results, } \\
\text { and a low concentration of } \\
\text { sample to matrix works best. } \\
\text { The matrix transforms the laser } \\
\text { energy into excitation energy } \\
\text { for the sample, which leads to } \\
\text { sputtering of analyte and matrix } \\
\text { ions from the surface of the } \\
\text { mixture. In this way energy } \\
\text { transfer is efficient and also the } \\
\text { analyte molecules are spared } \\
\text { excessive direct energy that } \\
\text { may otherwise cause } \\
\text { decomposition. } \\
\text { commercially ar anst } \\
\text { MALDI mass spectrometers } \\
\text { now have a pulsed nitrogen } \\
\text { laser of wavelength } 337 \text { nm. }\end{array}$ & $\begin{array}{l}\text { Gentle Ionization technique } \\
\text { High molecular weight } \\
\text { analyte can be ionized } \\
\text { Molecule need not be } \\
\text { volatile } \\
\text { Sub-picomole sensitivity } \\
\text { easy to obtain } \\
\text { Wide array of matrices }\end{array}$ & $\begin{array}{l}\text { MALDI matrix cluster ions } \\
\text { obscure low m/z species }(<600) \\
\text { Analyte must have very low } \\
\text { vapor pressure } \\
\text { Pulsed nature of source limits } \\
\text { compatibility with many mass } \\
\text { analyzers } \\
\text { Coupling MALDI with } \\
\text { chromatography can be } \\
\text { difficult } \\
\text { Analytes that absorb the laser } \\
\text { light can be problematic }\end{array}$ \\
\hline
\end{tabular}

